Manuscript Number: APEN-D-17-04563R1

Title: Bayesian Inference for Thermal Response Test Parameter Estimation and Uncertainty Assessment

Article Type: Research Paper

Keywords: Ground-source heat pump (GSHP); Thermal response test (TRT); Stochastic estimation; Bayesian inference; Uncertainty assessment; Parameter estimation

Corresponding Author: Dr. Wonjun Choi, Ph.D

Corresponding Author's Institution: University of Tokyo

First Author: Wonjun Choi, Ph.D

Order of Authors: Wonjun Choi, Ph.D; Hideki Kikumoto, PhD; Ruchi Choudhary, PhD; Ryoz Ooka, PhD

Abstract: The effective ground thermal conductivity and borehole thermal resistance constitute information needed to design a ground-source heat pump (GSHP). In situ thermal response tests (TRTs) are considered reliable to obtain these parameters, but interpreting TRT data by a deterministic approach may result in significant uncertainties in the estimates. In light of the impact of the two parameters on GSHP applications, the quantification of uncertainties is necessary. For this purpose, in this study, we develop a stochastic method based on Bayesian inference to estimate the two parameters and associated uncertainties. Numerically generated noisy TRT data and reference sandbox TRT data were used to verify the proposed method. The posterior probability density functions obtained were used to extract the point estimates of the parameters and their credible intervals. Following its verification, the proposed method was applied to in situ TRT data, and the relationship between test time and estimation accuracy was examined. The minimum TRT time of $36 \mathrm{~h}$ recommended by ASHRAE produced an uncertainty of $\pm 21 \%$ for effective thermal conductivity. However, the uncertainty of estimation decreased exponentially with increasing TRT time, and was $\pm 8.3 \%$ after a TRT time of $54 \mathrm{~h}$, lower than the generally acceptable range of uncertainty of $\pm 10 \%$. Based on the obtained results, a minimum TRT time of $50 \mathrm{~h}$ is suggested and that of $72 \mathrm{~h}$ is expected to produce sufficiently accurate estimates for most cases. 


\title{
Bayesian Inference for Thermal Response Test Parameter Estimation and Uncertainty Assessment
}

\author{
Wonjun Choi $^{1, *}$, Hideki Kikumoto ${ }^{1}$, Ruchi Choudhary ${ }^{2}$, Ryozo Ooka $^{1}$ \\ ${ }^{1}$ Institute of Industrial Science, The University of Tokyo, 4-6-1 Komaba, Meguro-ku, Tokyo 153-8505, Japan \\ ${ }^{2}$ Energy Efficient Cities Initiative, Department of Engineering, University of Cambridge, Trumpington Street, \\ Cambridge CB2 1PZ, UK \\ *Corresponding author. \\ Tel.: +81-3-5452-6434, Fax: +81-3-5452-6432, E-mail: wonjun@iis.u-tokyo.ac.jp
}

\begin{abstract}
The effective ground thermal conductivity and borehole thermal resistance constitute information needed to design a ground-source heat pump (GSHP). In situ thermal response tests (TRTs) are considered reliable to obtain these parameters, but interpreting TRT data by a deterministic approach may result in significant uncertainties in the estimates. In light of the impact of the two parameters on GSHP applications, the quantification of uncertainties is necessary. For this purpose, in this study, we develop a stochastic method based on Bayesian inference to estimate the two parameters and associated uncertainties. Numerically generated noisy TRT data and reference sandbox TRT data were used to verify the proposed method. The posterior probability density functions obtained were used to extract the point estimates of the parameters and their credible intervals. Following its verification, the proposed method was applied to in situ TRT data, and the relationship between test time and estimation accuracy was examined. The minimum TRT time of $36 \mathrm{~h}$ recommended by ASHRAE produced an uncertainty of $\sim \pm 21 \%$ for effective thermal conductivity. However, the uncertainty of estimation decreased exponentially with increasing TRT time, and was $\pm 8.3 \%$ after a TRT time of $54 \mathrm{~h}$, lower than the generally acceptable range of uncertainty of $\pm 10 \%$. Based on the obtained results, a minimum TRT time of $50 \mathrm{~h}$ is suggested and that of $72 \mathrm{~h}$ is expected to produce sufficiently accurate estimates for most cases.
\end{abstract}

Keywords: Ground-source heat pump (GSHP), Thermal response test (TRT), Minimum TRT time, Bayesian inference, Uncertainty assessment, Parameter estimation

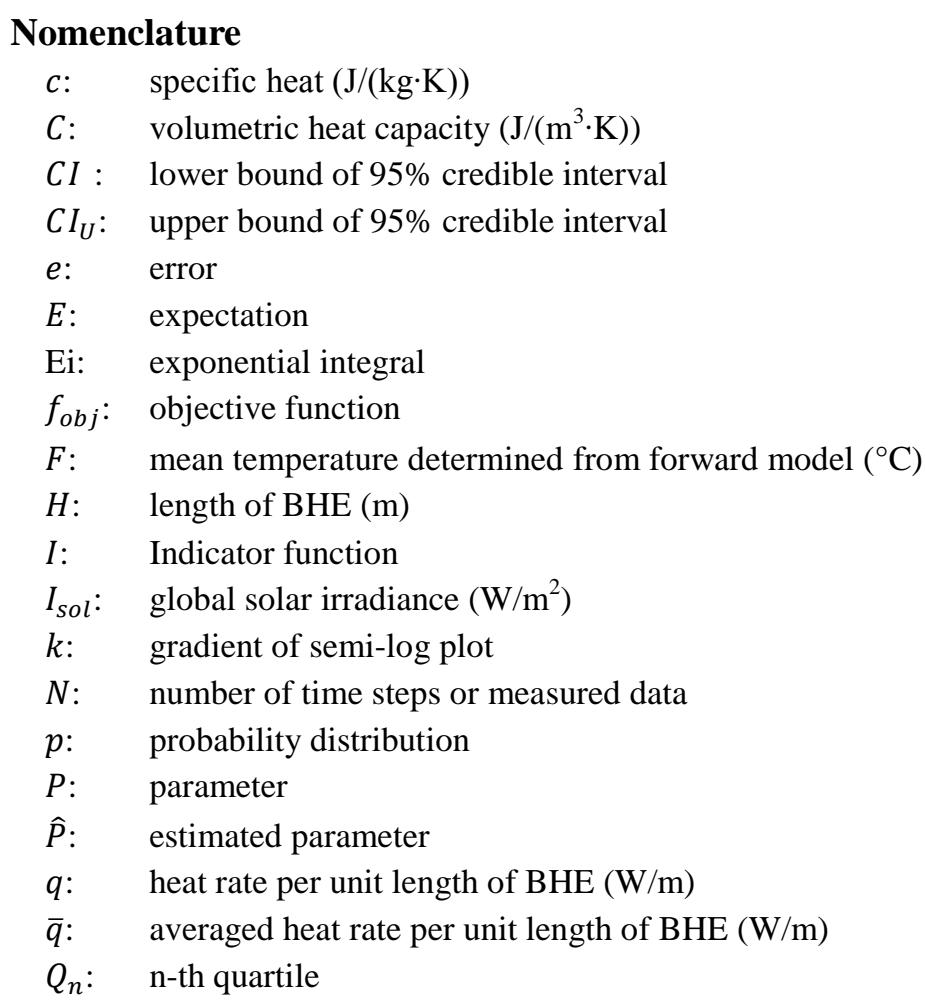




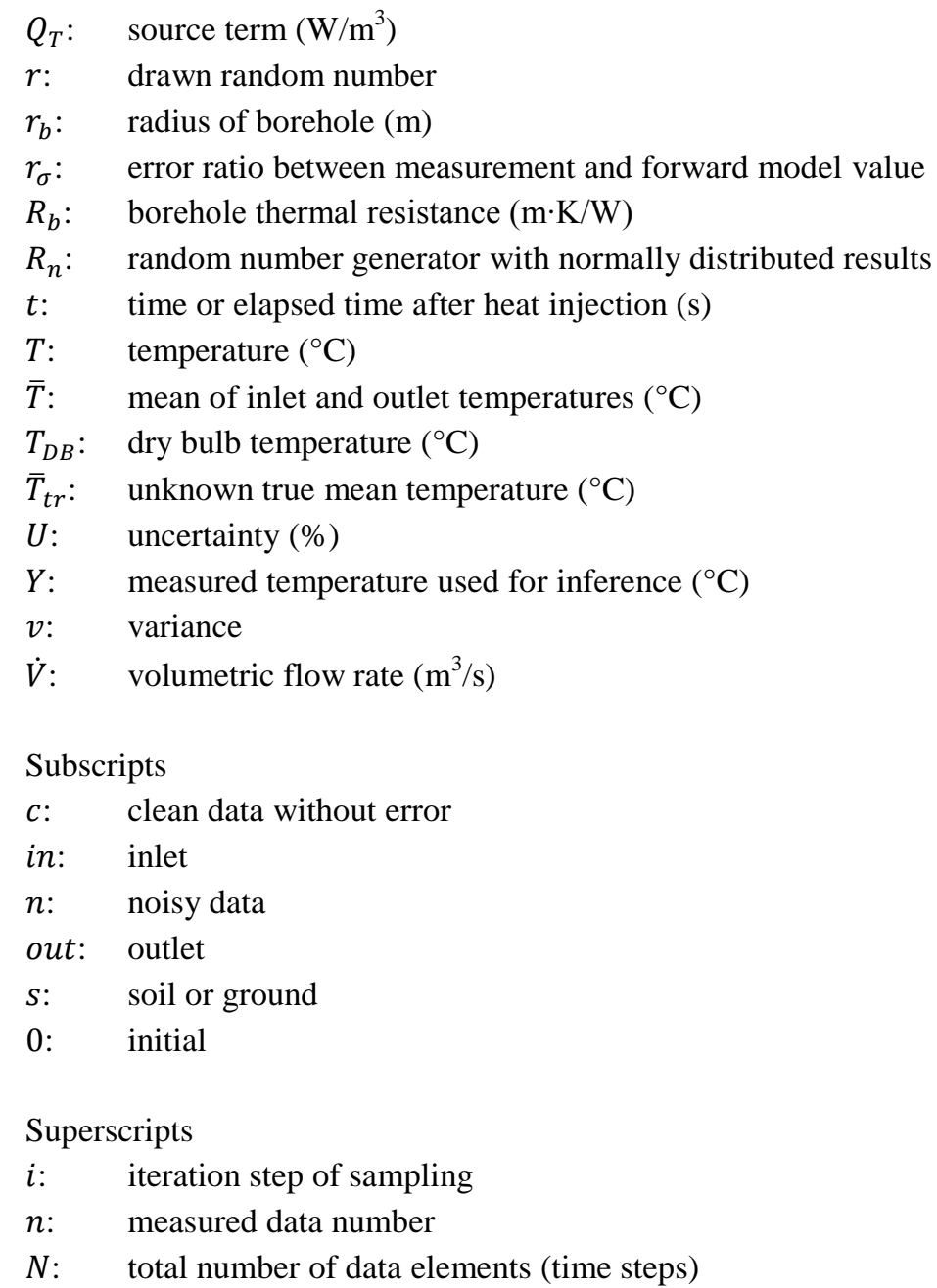

Greek letters

$\alpha: \quad$ thermal diffusivity $\left(\mathrm{m}^{2} / \mathrm{s}\right)$

$a_{r}: \quad$ acceptance ratio

$\lambda: \quad$ thermal conductivity $(\mathrm{W} /(\mathrm{m} \cdot \mathrm{K}))$

$\lambda_{\text {eff }}$ : effective thermal conductivity $(\mathrm{W} /(\mathrm{m} \cdot \mathrm{K}))$

$\rho: \quad$ density $\left(\mathrm{kg} / \mathrm{m}^{3}\right)$

$\gamma: \quad$ Euler-Mascheroni constant

$\sigma: \quad$ standard deviation

$\mathcal{N}: \quad$ normal distribution

$\mathfrak{R}$ : parameter space

$\mathcal{U}: \quad$ uniform distribution

Acronyms, abbreviations

CI: credible interval

MAP: maximum a posteriori

MCMC: Monte Carlo Markov Chain

PDF: probability density function

PM: posterior mean

PPDF: posterior probability density function

(All bold characters in the manuscript denote a vector or matrix.) 


\section{Introduction}

The ground has a much higher heat capacity than the air, and maintains a stable temperature. A ground-source heat pump (GSHP) that utilizes the ground as its heat source/sink can therefore be expected to perform better than an airsource heat pump. The ground heat exchanger (GHE) is a key component that affects the performance of a GSHP. Of the various types of GHEs, the most common is the vertical closed-loop GHE, the so-called borehole heat exchanger (BHE). In the design of a BHE, it is necessary to know the thermal conductivity of the ground and the thermal resistance of the borehole. Because the ground is a composite medium with highly site-specific thermal properties, it is difficult to establish the spatial distributions of the thermal properties. Consequently, the spatially averaged nearby thermal properties are estimated by in situ thermal response tests (TRTs) [1]. While a TRT test is expensive, it is recommended for any large installations because the parameters derived from it play a significant role in designing GSHP systems. Bernier [2] conducted an uncertainty analysis using the ASHRAE design method [3,4]. Among related parameters, the ground thermal conductivity had the most significant impact on the design length of the BHE. Assuming that the other parameters are accurately known, an uncertainty of $\pm 10 \%$ in thermal conductivity led to a $\pm 7.1 \%$ uncertainty in the length of the BHE. Robert and Gosselin [5] discussed the impact of ground thermal conductivity on initial and operation costs. They claimed that determining precise ground thermal conductivity via TRT is economically important, especially when the borefield is large.

To determine the values of ground thermal conductivity and borehole resistance from in situ TRT data, several inverse modeling techniques have been tested since Mogensen [6] first proposed the TRT estimation method. Research on the performance and accuracy of suitable inverse modeling techniques has been prolific because incorrect estimates of ground thermal conductivity and borehole resistance can increase the initial cost of the GSHP system or the probability of failure. The most well-known and frequently used is linear regression [7,8], which utilizes a simplified infinite line source (ILS) model (exponential integral approximated ILS model) [9,10]. Other parametric estimation techniques have been developed, and involve the combined use of a numerical or an analytical temperature response model and an optimization algorithm. One such method that has been employed in many studies [1,11-15] utilizes the Nelder-Mead simplex algorithm [16]. This is a heuristic optimization method. Gradient-based optimization methods have also been used in some previous studies. For example, Li and Lai [17] used the Levenberg-Marquardt method [18-20], Choi and Ooka [21] used the quasi-Newton method [22-25], and Bozzoli et al. [26] used the Gauss linearization method [27]. All these methods yield deterministic point estimates of ground thermal conductivity and thermal resistance of the borehole by minimizing the least squares norm. In this paper, we propose that the uncertainty quantification of parameters can improve their reliability and, thus, reduce initial cost and operational risks.

The causes of uncertainty in TRTs can be divided into two major categories. The first consists of errors due to contextual disturbances that occur during TRTs, and the second category consists of measurement errors, such as the intrinsic random error and the systematic error of utilized sensors. Considering that TRTs are conducted in outdoor environments, which cannot be completely controlled, the first error is a significant factor. Indeed, TRTs are vulnerable to large contextual uncertainties compared with fully controlled laboratory experiments. The effects of experimental disturbances on TRTs have been investigated by many researchers. For example, the effects of instability in voltage supply from the power grid or the power generator, and the resultant violation of the constant heating rate assumption of the ILS model have been examined [28-32], as well as those of heat exchange between an aboveground TRT setup and the outdoor environment [29,33-38]. If these experimental disturbances are not properly considered in the inverse model used for parameter estimation, the resultant inconsistencies can cause errors in the solution of the inverse problem $[21,38]$. With regard to measurement error, it is common to all types of measurements and can be reduced in this case by increasing the accuracy of the sensors used.

Given the importance of these estimations in GSHP applications, it is useful to quantify errors arising from contextual and measurement-related uncertainties, and propagate them as uncertainties in the estimated parameters. Regarding the uncertainty assessment of measurements and estimations, the ISO's Guide to the Expression of Uncertainty in Measurement (GUM) [39], which is based on classical frequentist statistics, is representative. In GUM, the sensitivity coefficients of all errors are first separately evaluated, as are their covariances (if necessary). The errors are then propagated to the parameters of interest. Through this process, it is possible to quantify the magnitudes of uncertainties in the estimated parameters. GUM-based uncertainty assessments have been conducted in many GSHP studies [40-47].

Although GUM seems relatively easy to implement, the requisite explicit specification of all major and minor sources of uncertainties in experimental conditions is subjective and error-prone. Moreover, there is no established method to quantify contextual uncertainties in GUM. Furthermore, as is the case with most frequentist techniques, one needs a 
relatively large volume of TRT test data to ensure reliable results, which can be expensive and time consuming. Finally, when more than two parameters need to be simultaneously estimated — as is the case in a TRT, which requires the estimation of effective thermal conductivity and borehole thermal resistance - quantification of the uncertainties considering the correlation of the parameters becomes challenging.

To overcome the limitations of conventional deterministic estimation methods and the GUM, we propose a Bayesian inference approach to the problem of quantifying uncertainties in parameters inferred from a TRT test. There has been a recent increase in the use of Bayesian inference techniques for solutions to inverse problems in heat transfer [48-54]. This has been facilitated by improved computational capabilities and numerical sampling techniques, such as the Markov chain Monte Carlo (MCMC) technique [49]. Bayesian approaches to uncertainty analysis leverage purely statistical information relating to uncertain parameters (derived from measurements) with expert knowledge. Bayesian inverse modeling consists of (1) assimilating prior expert knowledge concerning the uncertainty of the targeted parameterscreating "a priori" or "prior" distributions of uncertainty, and (2) drawing inferences about these parameters by combining prior knowledge with observations - using Bayes' formula to obtain the updated "a posteriori" or "posterior" distributions. When observations (e.g., statistical data) are plentiful, prior expert knowledge is not of great importance. In contrast, when observations are scarce, the quality of prior knowledge can have a significant impact on uncertainty analysis. This can be important when the duration of the TRT test is short. Bayesian inverse techniques have been shown to account for all relevant sources of uncertainty in prior knowledge and data, which can be efficiently and accurately reflected in the outcomes in the form of posterior probability density functions (PPDFs). The PPDF of the parameters provides information relating to parameter uncertainties that is difficult to directly obtain by classical deterministic approaches [55].

This paper tests the efficiency of a Bayesian approach to infer parameters from a TRT test and quantify uncertainties in the parameter values. A second objective is to examine the influence of the TRT test period on the reduction of uncertainties in the inferred parameters. Indeed, the optimal duration of a TRT test has been the subject of many studies. Although the ASHRAE Handbook [4] recommends a test period of 36-48 h, significantly different minimum durations have been proposed by researchers, such as 12-20 h [28], $30 \mathrm{~h} \mathrm{[57],} \mathrm{36-48} \mathrm{h} \mathrm{[29],} \mathrm{50} \mathrm{h} \mathrm{[59,60],} 53 \mathrm{~h}$ [61], and 60 h $[34,62]$.

For the major objective stated above, we employ a model based on a finite element method (FEM) to numerically generate $72 \mathrm{~h}$ of TRT data, from which actual measurement data are then mimicked by applying random error arising from sensors. Based on this mimicked noisy data, Bayesian inference is used to infer the PPDF of each parameter. The inferred values are compared with reference values, which are the estimated parameter values using numerical TRT data without random error. Moreover, the developed Bayesian inference framework was applied to sandbox reference TRT data [63] for additional verification.

For the second objective, we used in situ TRTs for up to $96 \mathrm{~h}$. A total of 11 time periods were considered using various test durations between 36 and $96 \mathrm{~h}$, in steps of six hours, to examine the relationship between the test duration and the range of uncertainty of the parameters. The $72 \mathrm{~h}$ of numerically generated TRT data were also analyzed in the same way to compare the magnitudes of uncertainty in the experimental data, including the measurement and the contextual error, and in numerical data, for only the measurement error. Based on the results, the advantages of stochastic estimation over conventional deterministic estimation are discussed.

\section{Generating TRT data and forward model}

\subsection{Numerical generation of TRT data}

TRT data was numerically generated using the FEM. The geometrical dimensions of the BHE and the thermal properties of each of its components are presented in Table 1 . The dimensions of the calculation domain were $15 \times 15 \times$ $80 \mathrm{~m}$ (length $\times$ width $\times$ depth). It was assumed that the borehole contained a single U-tube of length $50 \mathrm{~m}$, and that the geometry of the BHE was fully discretized. The numerical model considered only thermal conduction, with the exception of fluid flow through the U-tube, simplified as a one-dimensional (1D) flow on the basis of the law of Hagen-Poiseuille flow [64-66], to reduce the computation time needed to solve the Navier-Stokes equation. The 1D flow element was located at the center of the pipe. For the remaining area inside the pipe, pseudo-fluid elements with very high anisotropic thermal conductivity $(1000 \mathrm{~W} /(\mathrm{m} \cdot \mathrm{K})$ along the $\mathrm{x}$ and $\mathrm{y}$ directions and $0 \mathrm{~W} /(\mathrm{m} \cdot \mathrm{K})$ along the $\mathrm{z}$ direction) and low thermal capacity $\left(1 \mathrm{~J} / \mathrm{m}^{3} \mathrm{~K}\right)$ were used for radial heat transfer between the linear element and the pipe element. The details of this modeling method can be found in Ref. [38]. All thermal properties were assumed to be isotropic, homogeneous, and constant. The governing equation of the numerical model is as follows: 


$$
(\rho c)_{s} \frac{\partial T}{\partial t}-\lambda_{s} \nabla^{2} T=Q_{T}
$$

Table 1. Thermal properties and geometrical dimensions of the BHE used for the numerical TRT.

\begin{tabular}{lll}
\hline Component & Parameter [units] & Value \\
\hline Linear flow element & Thermal conductivity $[\mathrm{W} /(\mathrm{m} \cdot \mathrm{K})]$ & 0.6 \\
\cline { 2 - 3 } (Water) & Volumetric thermal capacity $\left[\mathrm{MJ} /\left(\mathrm{m}^{3} \cdot \mathrm{K}\right)\right]$ & 4.2 \\
\hline Pseudo-fluid in U-tube & Thermal conductivity $[\mathrm{W} /(\mathrm{m} \cdot \mathrm{K})]$ & 1000 \\
\cline { 2 - 3 } & Volumetric thermal capacity $\left[\mathrm{MJ} /\left(\mathrm{m}^{3} \cdot \mathrm{K}\right)\right]$ & $1 \times 10^{-6}$ \\
\hline U-tube & Outer diameter $[\mathrm{mm}]$ & 34 \\
\cline { 2 - 3 } (High-density polyethylene) & Inner diameter $[\mathrm{mm}]$ & 27 \\
\cline { 2 - 3 } & Shank spacing $[\mathrm{mm}]$ & 50 \\
\cline { 2 - 3 } & Thermal conductivity $[\mathrm{W} /(\mathrm{m} \cdot \mathrm{K})]$ & 0.38 \\
\cline { 2 - 3 } & Volumetric thermal capacity $\left[\mathrm{MJ} /\left(\mathrm{m}^{3} \cdot \mathrm{K}\right)\right]$ & 1.8 \\
\hline Borehole & Borehole depth $[\mathrm{m}]$ & 50 \\
\cline { 2 - 3 } & Borehole diameter $[\mathrm{mm}]$ & 165 \\
\hline Grout & Thermal conductivity $[\mathrm{W} /(\mathrm{m} \cdot \mathrm{K})]$ & 1.4 \\
\cline { 2 - 3 } & Volumetric thermal capacity $\left[\mathrm{MJ} /\left(\mathrm{m}^{3} \cdot \mathrm{K}\right)\right]$ & 2.0 \\
\hline Ground & Thermal conductivity $[\mathrm{W} /(\mathrm{m} \cdot \mathrm{K})]$ & 1.8 \\
\cline { 2 - 3 } & Volumetric thermal capacity $\left[\mathrm{MJ} /\left(\mathrm{m}^{3} \cdot \mathrm{K}\right)\right]$ & 2.5 \\
\hline
\end{tabular}

The heat injection rate and flow rate were set to $2.5 \mathrm{~kW}(50 \mathrm{~W} / \mathrm{m})$ and $15 \mathrm{~L} / \mathrm{min}$, respectively. An initial ground temperature of $17^{\circ} \mathrm{C}$ was assigned to the entire calculation domain. An adiabatic boundary condition was assigned to the top and lateral surfaces of the calculation domain, while a $17{ }^{\circ} \mathrm{C}$ Dirichlet boundary condition was assigned to the bottom surface. A time-varying Dirichlet boundary condition was applied to the inlet of the U-tube based on the outlet temperature of the previous time step, the heat injection rate, and the flow rate. The simulation was conducted for $72 \mathrm{~h}$ using time steps of $6 \mathrm{~min}$. The data obtained were thinned out at one-hour intervals and used for parameter estimation. Numerical data without random error are referred to hereinafter as clean data.

Measured data are generally affected by the intrinsic random error of the measurement sensor. To take this error into consideration, we applied a typical random sensor error to the numerically generated temperature and flow rate data. For temperatures measured using a Pt-100 (Class A) sensor, the general random error is $\pm(0.15+0.002 \cdot T)\left[{ }^{\circ} \mathrm{C}\right]$. In addition, considering that the random errors of sensors generally follow a normal distribution, the random error was mimicked in this study using a random number generator $R_{n}$ with outputs that follow the standard normal distribution. The obtained noisy temperature $T_{n}$ was given by

$$
T_{n}(t)=T(t) \pm(0.15+0.002 \cdot T(t)) R_{n}
$$

The noisy inlet and outlet temperatures of BHE are denoted by $T_{n, i n}$ and $T_{n, o u t}$, respectively, and their mean values are denoted by $\bar{T}_{n}$. When data $\bar{T}_{n}$ are used to infer parameters, we use a notation $\mathbf{Y}$ to indicate them $\left(Y\right.$ is one $\bar{T}_{n}$ at a certain elapsed time).

In the case of the flow rate, it was assumed to be measured by an electromagnetic flow meter, which has a random error of $\pm 0.6 \%$. In contrast to the temperature, the instantaneous measured value of which is used for the estimation, the flow rate is relatively constant during a TRT, and an average value determined from multiple independent measurements can thus be adopted. Assuming that the measurement was conducted at 30-s intervals and that TRT data obtained at 1-h intervals were used for the parameter estimation, an accuracy of $\pm 0.006 / \sqrt{120}$ can be expected based on the central limit theorem. The measured flow rate $\dot{V}_{n}$ was thus obtained as

$$
\dot{V}_{n}(t)=\dot{V}(t) \pm(0.006 \cdot \dot{V}(t)) R_{n} / \sqrt{120}
$$

Based on these measurement datasets containing random sensor errors, the heat injection rate per unit length of the 
BHE was determined using the following equation:

$$
q(t)=\rho c \dot{V}_{n}(t)\left(T_{n, \text { in }}(t)-T_{n, o u t}(t)\right) / H
$$

The numerically generated data for temperature response (inlet, outlet, and mean) and the volumetric flow rate for $72 \mathrm{~h}$ are shown in Fig. 1. The dotted lines represent the noisy temperatures and the solid black line represents the mean temperature without random error.

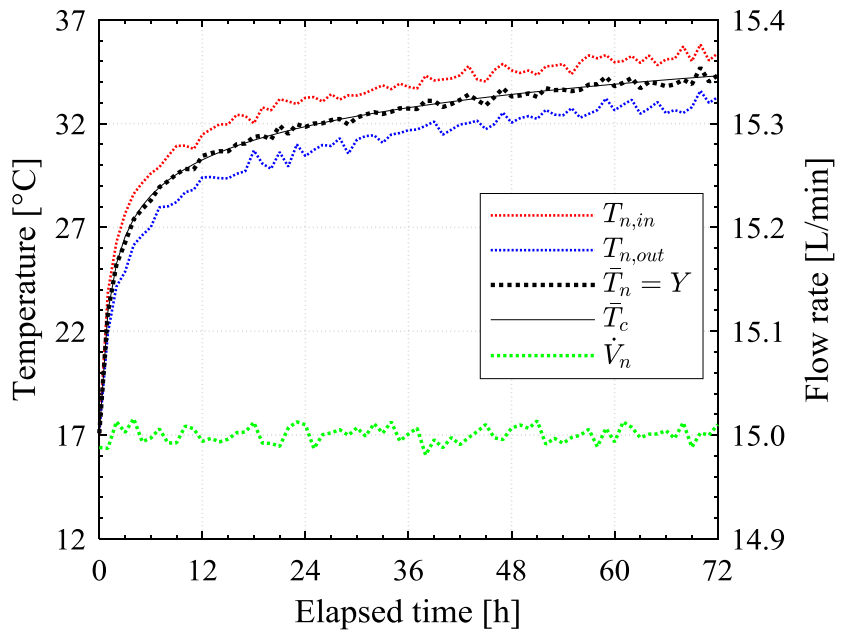

Fig. 1. Numerically generated temperature and flow rate data $\left(T_{n, i n}\right.$ : noisy inlet temperature, $T_{n, \text { out }}$ : noisy outlet temperature, $\bar{T}_{n}=Y$ : noisy mean temperature, $\bar{T}_{c}$ : clean mean temperature (data without noise), $\dot{V}_{n}:$ noisy volumetric flow rate).

\subsection{Forward model}

A physical model is required to infer the ground thermal conductivity and borehole resistance from temperature and flow rate measurements. Such a model is referred to as a forward model or direct model and its calculation is regarded as a forward problem. The classical infinite line source model $[9,10]$ was used as the forward model in this study. This wellknown analytical model is obtained using a 1D heat equation with a boundary condition consisting of a constant heat flux from the heat source in the homogeneous medium. The mean fluid temperature (arithmetic mean of the inlet and outlet fluid temperatures) obtained by the ILS model is given by

$$
F=\frac{\bar{q}}{4 \pi \lambda_{e f f}} \operatorname{Ei}\left(\frac{C_{s} r_{b}^{2}}{4 \lambda_{e f f} t}\right)+R_{b} \bar{q}+T_{0}
$$

Here, $F$ is the mean fluid temperature, $\bar{q}$ is the averaged heat rate during the TRT (calculated using Eq. (4)), $\lambda_{e f f}$ is the effective thermal conductivity, $C_{s}$ is the volumetric thermal capacity of the ground, $t$ is the time duration of the TRT, $R_{b}$ is the borehole thermal resistance, and $T_{0}$ is the initial ground temperature.

The most common deterministic estimation method utilizes a simplified ILS model, which is an approximation of the exponential integral in Eq.(5). The exponential integral can be described as the sum of the terms of an infinite series, although only the first two terms are considered in its practical application. A detailed description of this simplification can be found in Refs. [7,8]. The simplified ILS model is expressed as follows:

$$
F=\underbrace{\frac{\bar{q}}{4 \pi \lambda_{e f f}}}_{k} \ln t+\frac{\bar{q}}{4 \pi \lambda_{e f f}}\left\{\ln \left(\frac{4 \lambda_{e f f}}{C_{s} r_{b}^{2}}\right)-\gamma\right\}+R_{b} \bar{q}+T_{0}
$$

The effective thermal conductivity can be estimated using the linear relationship between the temperature response and the logarithmic time. That is, if the gradient $k$ is obtained by ordinary least squares, the effective thermal conductivity 
can be determined using

$$
\lambda_{\text {eff }}=\frac{\bar{q}}{4 \pi k}
$$

The estimation procedure based on Eqs. (6) and (7) is here referred to as the conventional or deterministic estimation method.

Although the ILS model assumes a homogeneous ground, the thermal properties of a BHE and filling material differ from those of the ground. Additionally, the borehole thermal resistance $R_{b}$ in Eq. (5), a representation of the thermal resistance between the borehole wall and the fluid, is based on the assumption of a steady state. The early temperature response is thus not reliable, and the temperature response data for the elapsed time from $14 \mathrm{~h}$ onward was used for the present estimation.

\subsection{Deterministic estimation}

Based on the generated clean and noisy data, the simplified ILS model was used for deterministic estimations (i.e., using the gradient of the temperature versus the logarithmic time, represented by Eqs. (6) and (7). The behaviors of the sequential estimations from $15 \mathrm{~h}$ onward (e.g., the estimation at $15 \mathrm{~h}$ used data from $14 \mathrm{~h}$ to $15 \mathrm{~h}$, and the estimation at 60 $\mathrm{h}$ used data from $14 \mathrm{~h}$ to $60 \mathrm{~h}$ ) are shown in Fig. 2 and the final estimated values are presented in Table 2. As shown in Fig. 2, the estimations based on noisy data exhibited significant instability whereas those based on clean data were stable, and gradually converge to a $\lambda_{\text {eff }}$ value of $1.78 \mathrm{~W} /(\mathrm{m} \cdot \mathrm{K})$. Because the thermal conductivity of the grout and the pipe were set to $1.4 \mathrm{~W} /(\mathrm{m} \cdot \mathrm{K})$ and $0.38 \mathrm{~W} /(\mathrm{m} \cdot \mathrm{K})$, respectively, their effect reduced the estimation of $\lambda_{\text {eff }}$ to lower than 1.8 $\mathrm{W} /(\mathrm{m} \cdot \mathrm{K})$, which was the value set for ground thermal conductivity in the numerical FEM (Table 1).

Parameter estimates derived from an actual TRT are likely to be more unstable than those in Fig. 2 owing to the effects of other disturbances, such as heat exchange between the aboveground TRT circuit and the outdoor environment, and instability in the supply voltage. This is examined in Section 5. The estimated $\lambda_{\text {eff }}$ and $R_{b}$ values after a test lasting 72 $\mathrm{h}$ were, respectively, $1.78 \mathrm{~W} /(\mathrm{m} \cdot \mathrm{K})$ and $0.162 \mathrm{~m} \cdot \mathrm{K} / \mathrm{W}$ based on clean data, and $1.802 \mathrm{~W} /(\mathrm{m} \cdot \mathrm{K})$ and $0.169 \mathrm{~m} \cdot \mathrm{K} / \mathrm{W} \mathrm{based}$ on noisy data. These are regarded as reference values for comparison with the results of the stochastic approach.

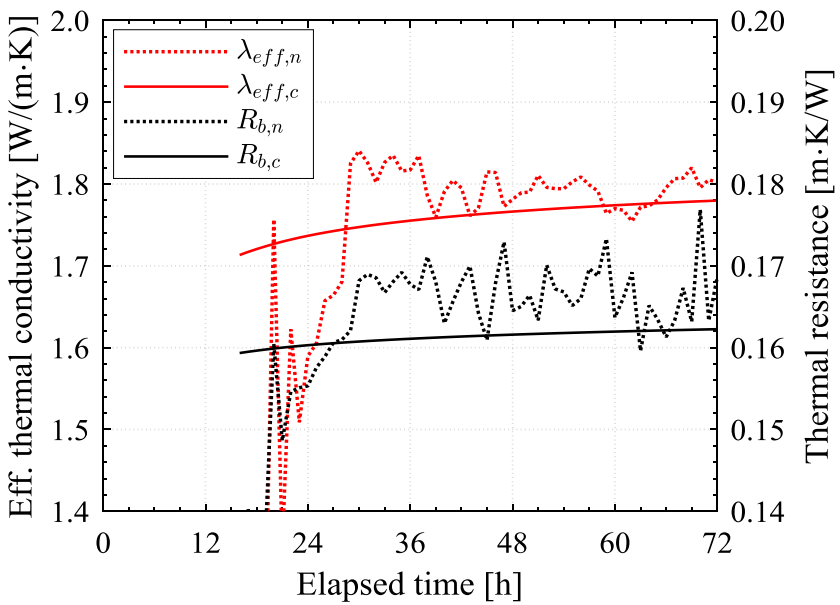

Fig. 2. Sequential estimations based on clean and noisy data.

\section{Parameter estimation using Bayesian inference}

The Bayesian inference approach can be used to solve an inverse problem by formulating a probabilistic description of the uncertainties of the unknown parameters and the measured data. The Bayesian approach presents the initially available information (or expert judgment) about the unknown parameters and their uncertainties in the form of a prior probability density function. By combining this function with a likelihood function, the posterior probability density function (PPDF) can be obtained. 


\subsection{Definition of parameter space}

In the likelihood function, which is described in detail later in Section 3.3, it is necessary to quantify the difference between the modeled temperature $F$ and the measured temperature $Y$. Thus, we define a parameter $r_{\sigma}$, which is a measure of the error ratio between $Y$ and $F$ normalized by the difference between $Y$ and the initial ground temperature $T_{0}$.

$$
r_{\sigma}=\left|\frac{Y-F}{Y-T_{0}}\right|
$$

It should be noted that $r_{\sigma}$ does not represent the deviation from the unknown true temperature, but is an indication of the error between the measured temperature subject to the measurement error and the modeled temperature, which does not precisely reproduce the actual physical phenomenon. Because of the limited or lack of information about $r_{\sigma}$, we consider it as a hyperparameter and infer it along with the parameter vector $\mathbf{P}$.

\subsection{Bayes' theorem}

A primary interest of Bayesian inference is the determination of the PPDFs, which are the conditional probability distributions of the parameters of given measurement data Y. The PPDFs are specifically defined using Bayes' theorem, based on which the conditional probability of the parameter vector $\mathbf{P}$ and $r_{\sigma}$ is also expressed as follows for a given measurement data $\mathbf{Y}$ :

$$
p\left(\mathbf{P}, r_{\sigma} \mid \mathbf{Y}\right)=\frac{p\left(\mathbf{Y} \mid \mathbf{P}, r_{\sigma}\right) p\left(\mathbf{P}, r_{\sigma}\right)}{p(\mathbf{Y})}
$$

where $p\left(\mathbf{P}, r_{\sigma} \mid \mathbf{Y}\right)$ denotes the posterior distribution given the measurement data $\mathbf{Y}, p\left(\mathbf{Y} \mid \mathbf{P}, r_{\sigma}\right)$ denotes the likelihood of $\mathbf{P}$ and $r_{\sigma}$ for a given $\mathbf{Y}, p\left(\mathbf{P}, r_{\sigma}\right)$ denotes the prior of the uncertain parameters, and $p(\mathbf{Y})$ denotes the evidence.

Although the evidence $p(\mathbf{Y})$ is very difficult to determine, it is known to be constant. Therefore, Eq. (10) can be rewritten as the following proportional expression without the denominator of the right-hand side:

$$
p\left(\mathbf{P}, r_{\sigma} \mid \mathbf{Y}\right) \propto p\left(\mathbf{Y} \mid \mathbf{P}, r_{\sigma}\right) p\left(\mathbf{P}, r_{\sigma}\right)
$$

\subsection{Likelihood}

As noted earlier, both the measured and modeled temperatures are subject to uncertainties. The measurement error $e_{y}$ originates from the intrinsic error of the sensors, while the model error $e_{f}$ is due to errors in the model (because the model is an approximation of the true physical phenomenon). If the unknown true temperature is denoted by $\bar{T}_{t r}$, the measured and modeled temperatures can be expressed as Eqs. (12) and (13), respectively.

$$
\begin{aligned}
& Y^{n}=\bar{T}_{t r}^{n}+e_{y}^{n} \\
& F^{n}=\bar{T}_{t r}^{n}+e_{f}^{n}
\end{aligned}
$$

where the superscript $n$ describes the time step.

The measurement and model errors were assumed to be independent to each other and follow a normal distribution with a mean zero and variances of $\left(\sigma_{y}^{n}\right)^{2}=v_{y}^{n}$ and $\left(\sigma_{f}^{n}\right)^{2}=v_{f}^{n}$, respectively. Under these assumptions, the likelihood functions with respect to the measured temperature and true temperature are expressed as Eq. (14) and Eq. (15), 
respectively.

$$
\begin{gathered}
p\left(\mathbf{Y} \mid \bar{T}_{t r}\right)=\prod_{n=1}^{N} \frac{1}{\sqrt{2 \pi v_{y}^{n}}} \exp \left[-\frac{\left(Y^{n}-\bar{T}_{t r}^{n}\right)^{2}}{2 v_{y}^{n}}\right] \\
p\left(\bar{T}_{t r} \mid \mathbf{P}\right)=\prod_{n=1}^{N} \frac{1}{\sqrt{2 \pi v_{f}^{n}}} \exp \left[-\frac{\left(\bar{T}_{t r}^{n}-F^{n}(\mathbf{P})\right)^{2}}{2 v_{f}^{n}}\right]
\end{gathered}
$$

where $N$ is the total number of time steps.

Based on the two predefined likelihood functions, the likelihood $p(\mathbf{Y} \mid \mathbf{P})$ can be expressed as follows:

$$
p(\mathbf{Y} \mid \mathbf{P})=\int_{-\infty}^{\infty} p\left(\mathbf{Y} \mid \bar{T}_{t r}\right) p\left(\bar{T}_{t r} \mid \mathbf{P}\right) \mathrm{d} \bar{T}_{t r}
$$

Equation (16) describes the marginalization of the likelihood with respect to the unknown $\bar{T}_{t r}$. By substituting Eqs. (14) and (15) into Eq. (16), the following marginalized likelihood function is obtained:

$$
p(\mathbf{Y} \mid \mathbf{P})=\prod_{n=1}^{N} \frac{1}{\sqrt{2 \pi\left(v_{y}^{n}+v_{f}^{n}\right)}} \cdot \exp \left[-\frac{1}{2} \sum_{n=1}^{N} \frac{\left(Y^{n}-F^{n}(\mathbf{P})\right)^{2}}{v_{y}^{n}+v_{f}^{n}}\right]
$$

The mathematical derivation of Eq. (17) from Eq. (16) is presented in Appendix A.

If the measurement and model errors and the measured and modeled temperatures on the right-hand side of Eq. (17) are known, the likelihood $p(\mathbf{Y} \mid \mathbf{P})$ can be calculated. The measurement and model errors in Eq. (17) are difficult to quantify. We set the sum of the two variances as a hyperparameter to be estimated by introducing the new variable $r_{\sigma}$, the error ratio, as described in Section 3.1.1. The sum of the two variances can be defined as follows:

$$
v_{y}^{n}+v_{f}^{n}=\left(\sigma_{y}^{n}\right)^{2}+\left(\sigma_{f}^{n}\right)^{2} \approx\left\{r_{\sigma}\left(Y^{n}-T_{0}\right)\right\}^{2}
$$

By substituting Eq. (18) into Eq. (17), the likelihood function can be rewritten as follows:

$$
p\left(\mathbf{Y} \mid \mathbf{P}, r_{\sigma}\right) \propto \frac{1}{r_{\sigma}^{N}} \exp \left[-\frac{1}{2} \sum_{n=1}^{N} \frac{\left(Y^{n}-F^{n}(\mathbf{P})\right)^{2}}{\left(r_{\sigma}\left(Y^{n}-T_{0}\right)\right)^{2}}\right]
$$

\subsection{Prior probability of parameters}

In Bayesian inference, priors play an important role in constraining the parameters within plausible bounds. The prior distributions of the uncertain parameters $\lambda_{e f f}, R_{b}$, and $r_{\sigma}$ can be set in many ways. For example, the range of $\lambda_{e f f}$ can be bound based on the drill $\log$ of the borehole or the results of previous TRTs conducted near the site. The plausible range of $R_{b}$ can be estimated using various analytical models. Reviews and information about the accuracies of many $R_{b}$ models can be found in Refs. [67-70]. Once the TRT data are obtained, the estimations obtained by a conventional deterministic approach can also be used to predict the likely location of the mode of the prior probability density function. Regarding the error ratio $r_{\sigma}$, it is known to be positive definite, and its upper bound can be set to an arbitrarily large value, such as 0.2 . We thus set the ranges of the parameters as follows, and an indicator function $I$ was used to represent the bounds of the parameter space:

$$
\begin{gathered}
\lambda_{e f f}=[1.2,3.5] \\
R_{b}=[0.1,0.2]
\end{gathered}
$$




$$
r_{\sigma}=(0,0.2]
$$

The choice of a prior is very application-specific. Once the lower and upper limits are set based on available information or within a sufficiently large range, the prior distribution of each parameter must then be defined. However, in the absence of sufficient information on the distribution, it is difficult to be certain about the shape of the prior probability distribution. Given our carefully assigned (and narrow) plausible bounds on uncertain parameters, it is rational to consider the priors as uniformly distributed in the parameter space $\mathfrak{R}$.

$$
p\left(\mathbf{P}, r_{\sigma}\right)=\text { constant, } \quad\left(\mathbf{P}, r_{\sigma}\right) \in \Re
$$

\subsection{Posterior evaluation using Markov chain Monte Carlo method}

Because we set the priors to be uniformly distributed within their given ranges, the posterior only depended on the likelihood. The bounds of the parameter space were considered in the calculation of the posterior using the indicator function $I$. The final form of the posterior probability including the indicator function can be expressed as follows:

$$
\begin{aligned}
& p\left(\mathbf{P}, r_{\sigma} \mid \mathbf{Y}, I\right) \propto p\left(\mathbf{Y} \mid \mathbf{P}, r_{\sigma}, I\right) p\left(\mathbf{P}, r_{\sigma} \mid I\right) \\
& \quad \propto I\left(\left(\mathbf{P}, r_{\sigma}\right) \in \Re\right) \frac{1}{r_{\sigma}^{N}} \exp \left[-\frac{1}{2} \sum_{n=1}^{N} \frac{\left(Y^{n}-F^{n}(\mathbf{P})\right)^{2}}{\left(r_{\sigma}\left(Y^{n}-T_{0}\right)\right)^{2}}\right]
\end{aligned}
$$

After defining the prior and likelihood functions, the PPDF of each parameter can be computed. The PPDF can be obtained by analytical integration. It is, however, necessary to define the exact form of the probability distribution of each variable that often cannot be definitively determined. Even if it is defined, evaluating the distribution will still be numerically very complex. The use of a numerical method such as the MCMC method to evaluate the PPDF is a more flexible and realistic approach. The MCMC method is well-established and several versions can be found in [71,72]. The Metropolis-Hastings algorithm [73-75] was used to evaluate the PPDFs in the present study. 


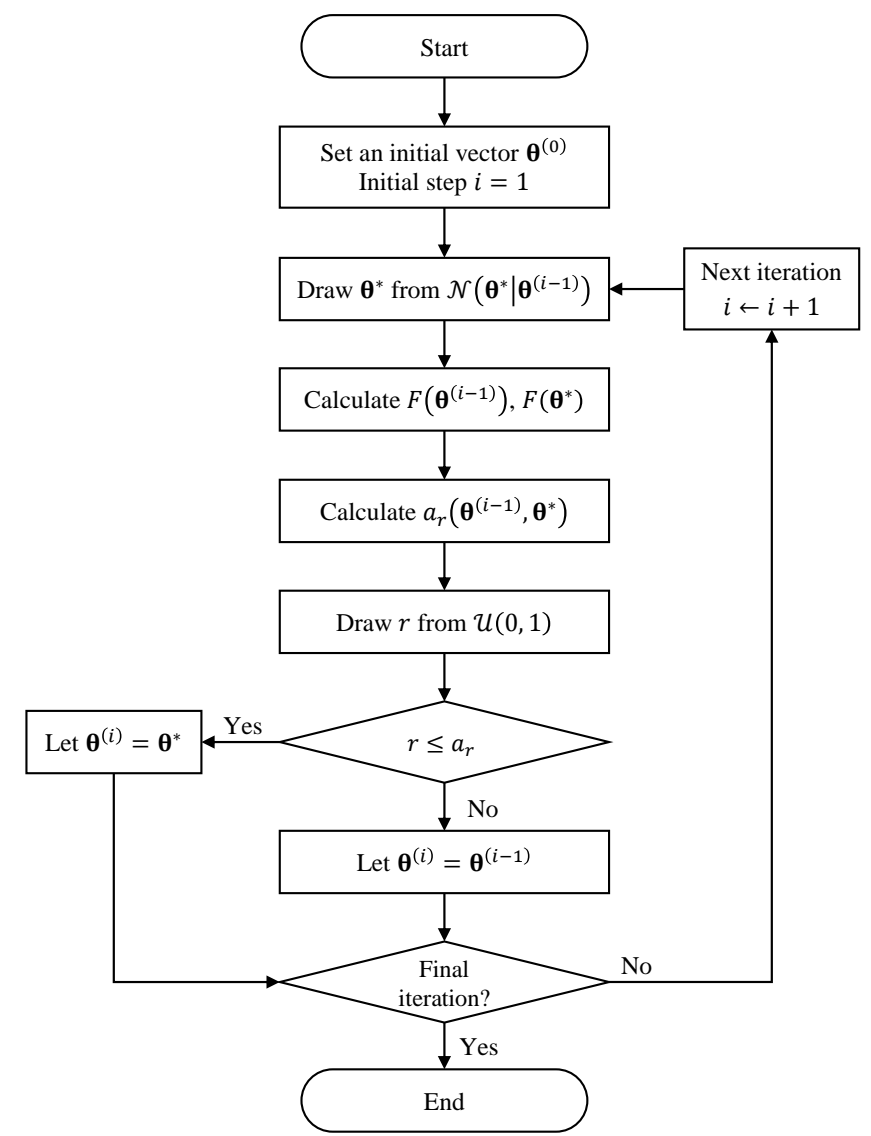

Fig. 3. Flowchart of the Metropolis-Hastings algorithm.

The flowchart of the Metropolis-Hastings sampling algorithm is shown in Fig. 3. For brevity, we here define a new parameter vector $\boldsymbol{\theta}=\left(\mathbf{P}, r_{\sigma}\right)$. Firstly, the $i$-th sampling iteration is denoted by $\boldsymbol{\theta}^{(i)}$. The sampling begins with an arbitrary initial parameter $\boldsymbol{\theta}^{(0)}$. From the initial parameter, a candidate parameter $\boldsymbol{\theta}^{*}$ for the next sampling is decided using a normal distribution with a mean value of $\boldsymbol{\theta}^{(i-1)}$ and variance of $7 \%$ of $\boldsymbol{\theta}^{(i-1)}$. This variance of $7 \%$ was determined by trial and error to prevent the parameter search from being stuck at a local point or yielding a large correlation among the drawn samples. A new parameter state $\boldsymbol{\theta}^{*}$ is then obtained based on the given state $\boldsymbol{\theta}^{(i-1)}$ as follows:

$$
\boldsymbol{\theta}^{*}=\mathcal{N}\left(\boldsymbol{\theta}^{(i-1)},\left(0.07 \cdot \boldsymbol{\theta}^{(i-1)}\right)^{2}\right)
$$

When a candidate parameter $\boldsymbol{\theta}^{*}$ is outside the parameter space, the indicator function $I$ becomes zero, and the sampled parameter of the given step is thus abandoned. The parameter of the previous step is then used in the next iteration, $\boldsymbol{\theta}^{(i-1)} \rightarrow \boldsymbol{\theta}^{(i)}$. If the candidate parameter $\boldsymbol{\theta}^{*}$ is within the parameter space, the temperature $F$ would be calculated using two parameter vectors $\mathbf{P}^{(i-1)}$ and $\mathbf{P}^{*}$ to evaluate the following acceptance ratio:

$$
a_{r}=\min \left[1, \frac{p\left(\boldsymbol{\theta}^{*} \mid \mathbf{Y}, I\right)}{p\left(\boldsymbol{\theta}^{(i-1)} \mid \mathbf{Y}, I\right)}\right]
$$

If $a_{r}=1, \boldsymbol{\theta}^{*}$ is accepted. Otherwise (if $a_{r}<1$ ), a random number $r$ is generated from a uniform distribution within the interval $(0,1)$. Subsequently, by comparing $a_{r}$ and $r, \boldsymbol{\theta}^{*}$ is accepted or rejected based on the following criterion:

$$
\boldsymbol{\theta}^{(i)}=\left\{\begin{array}{cc}
\boldsymbol{\theta}^{*} & \text { if } r \leq a_{r} \\
\boldsymbol{\theta}^{(i-1)} & \text { if } r>a_{r}
\end{array}\right.
$$


By iterating this process, samples of the estimated parameters are obtained. If a sufficiently large number of samples is obtained, the numerical evaluation of PPDF can be achieved based on the law of large numbers. The sampling was repeated $5 \times 10^{5}$ times in this study. However, because the early iteration steps are significantly dependent on the initial values, the first $1 \times 10^{5}$ samples were neglected, with the subsequent $4 \times 10^{5}$ samples used to evaluate the PPDF.

Based on the obtained PPDFs, the point estimates and their credible intervals can be obtained. We used the posterior mean (PM) or maximum a posteriori (MAP) estimator to obtain a point estimate from the PPDF as follows:

$$
\begin{gathered}
\hat{P}_{\mathrm{PM}}=E(P \mid \mathbf{Y}) \\
\hat{P}_{\mathrm{MAP}}=\arg \max _{P} p(P \mid \mathbf{Y})
\end{gathered}
$$

Further, the percent uncertainty of a parameter, $U$ [\%], can be determined from the lower and upper bounds of the $95 \%$ credible interval, and the PM of PPDF is denoted by $C I_{L}, C I_{U}$, and $\hat{P}_{\mathrm{PM}}$, respectively, as follows:

$$
U=\frac{0.5\left(C I_{U}-C I_{L}\right)}{\widehat{P}_{\mathrm{PM}}} \cdot 100
$$

\section{Bayesian inference using numerically generated data}

To generate the PPDFs of the parameters, $5 \times 10^{5}$ samplings were conducted using the Metropolis-Hastings algorithm. As in the deterministic estimation, the TRT data for 14-72 $\mathrm{h}$ were used to calculate the posterior distribution. The deterministic estimations based on the noisy data, namely $1.802 \mathrm{~W} /(\mathrm{m} \cdot \mathrm{K})$ and $0.169 \mathrm{~m} \cdot \mathrm{K} / \mathrm{W}$ (Fig. 2), were used for the first iteration of the MCMC sampling. As noted earlier, because the sampling results of the initial iterations were significantly affected by the values of the initial parameter, the first $1 \times 10^{5}$ results were not considered. The remaining $4 \times 10^{5}$ sampling results for $\lambda_{e f f}, R_{b}$, and $r_{\sigma}$ are shown in Fig. 4. The red dashed-dotted lines in the figure represent the reference values of the respective parameters, which were deterministically obtained using clean data (Fig. 2).

For each of $\lambda_{e f f}$ and $R_{b}$, the sampling results fluctuate around the reference value. In the case of $r_{\sigma}$, the generated samples exhibit prominent peaks only in the upper region, and they are always higher than $0.9 \%$. 

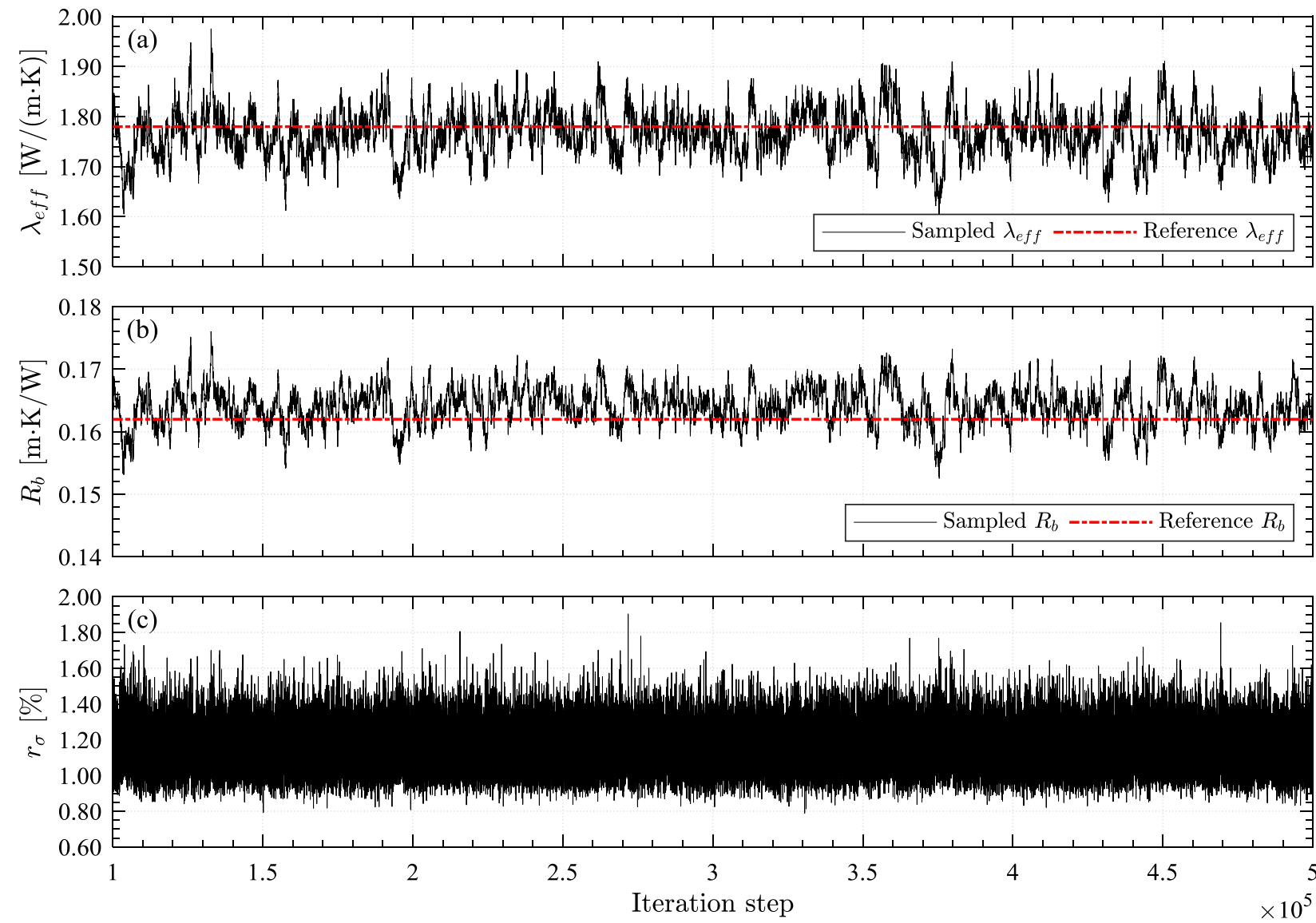

Fig. 4. Sampling results of the different parameters: (a) effective thermal conductivity (reference value $=1.78$ $\mathrm{W} /(\mathrm{m} \cdot \mathrm{K})$ ), (b) borehole thermal resistance (reference value $=0.162 \mathrm{~m} \cdot \mathrm{K} / \mathrm{W})$, and (c) error ratio.

The PPDFs and box plots of $\lambda_{\text {eff }}$ and $R_{b}$ obtained from the considered $4 \times 10^{5}$ sampling datasets are shown in Fig. 5, while those of the error ratio $r_{\sigma}$ are shown in Fig. 6. The PPDFs of $\lambda_{\text {eff }}$ and $R_{b}$ have a normal distribution and strong unimodality with a short symmetric tail. In contrast, the PPDF of $r_{\sigma}$ is slightly skewed (relatively longer tail in the upper region), similar to a Gamma distribution. From the sampling results and PPDFs, we speculate that the normalized error between the measured data and forward model temperatures is always larger than $\sim 0.85 \%$, mostly within $1.0-1.4 \%$, although it sometimes increased to $1.9 \%\left(r_{\sigma}\right.$ values greater than $1.5 \%$ were considered outliers and are not shown in Fig. $6)$. This relatively large error may occur when the random errors of the inlet and outlet temperature sensors are in the same direction (e.g., either positive or negative errors in both the inlet and outlet sensors, respectively). It should be noted that the ratio $r_{\sigma}$ is an indication of the discrepancy between the measured temperature and the temperature estimated by the forward model, and not the uncertainty in the estimated parameter vector $\mathbf{P}$. 

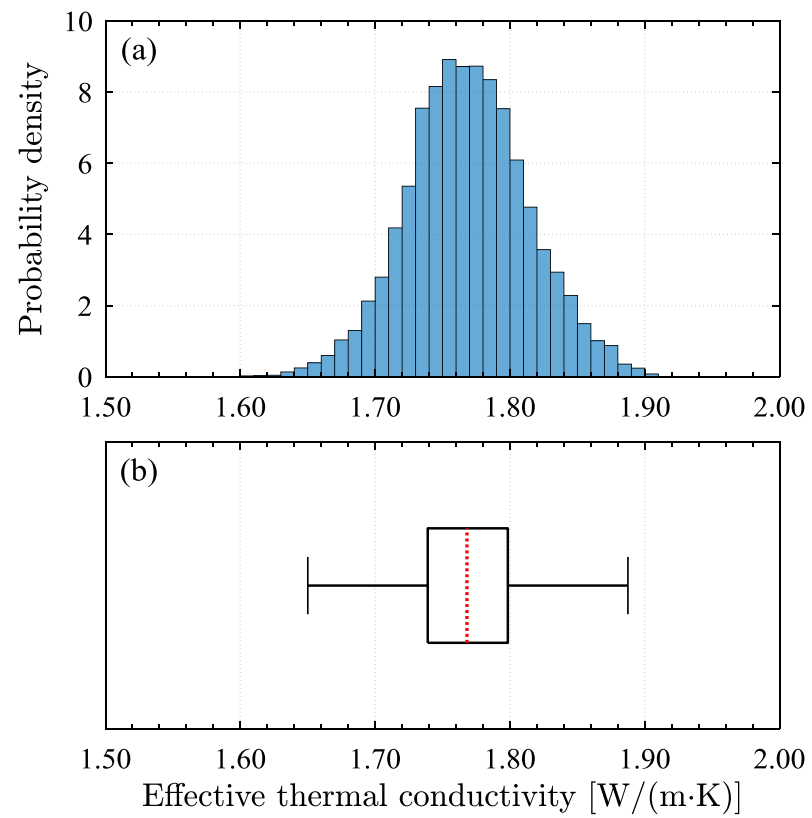

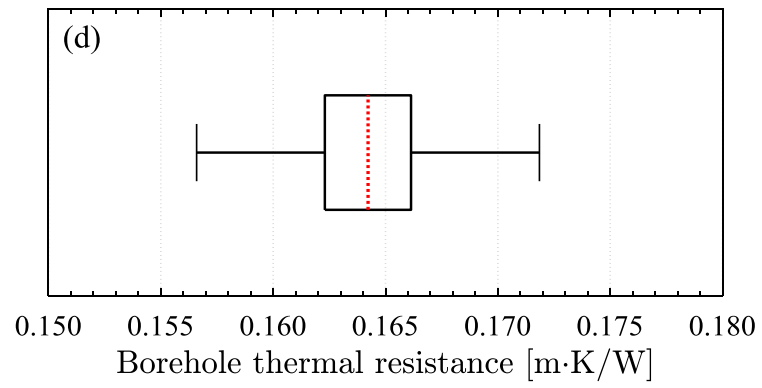

Fig. 5. Normalized probability density functions (PDFs) and box plots: (a) PDF of $\lambda_{e f f}$, (b) box plot of $\lambda_{e f f}$, (c) PDF of $R_{b}$, and (d) box plot of $R_{b}$. The lower and upper ends of a box represent the first and third quartiles, respectively, while the red band inside the box denotes the median. The left and right ends of a whisker represent $Q_{1}-1.5\left(Q_{3}-Q_{1}\right)$ and $Q_{3}+1.5\left(Q_{3}-Q_{1}\right)$, respectively. The outliers are not shown in the box plots.
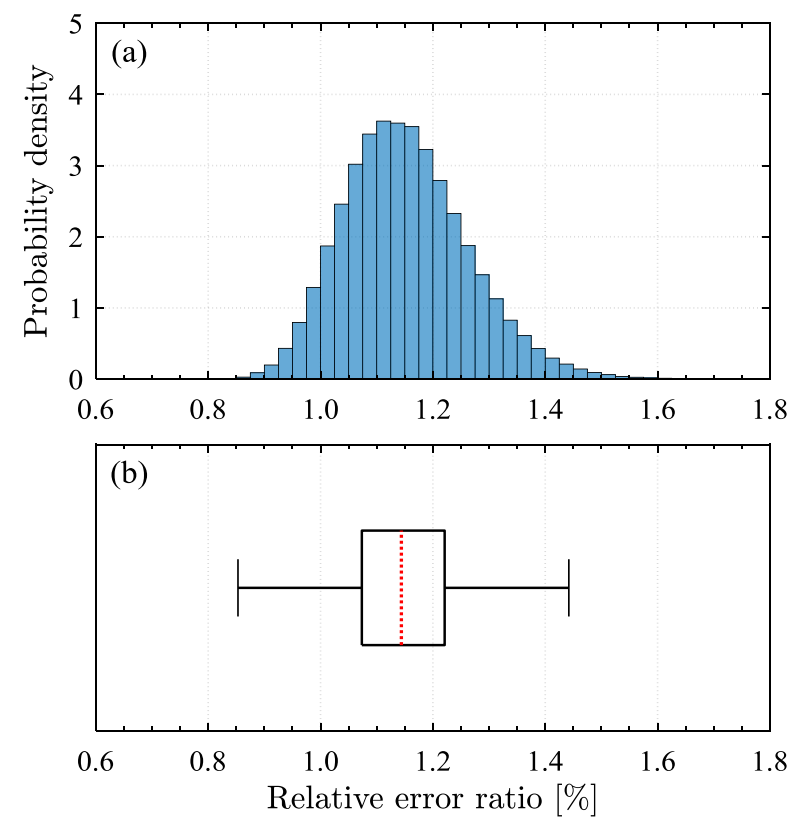

Fig. 6 (a) Normalized probability density function and (b) box plot of $r_{\sigma}$.

Based on the PPDFs, the point estimates were obtained using the PM and MAP estimators, as well as the 95\% credible intervals. The results are presented in Table 2. For comparison, the table also includes the point estimates obtained by the deterministic approach. Because the PPDFs of $\lambda_{e f f}$ and $R_{b}$ are unimodal and almost symmetric, there are little differences between the results of the PM and MAP. The estimated $\lambda_{\text {eff }}$ is slightly smaller than the reference value of $1.78 \mathrm{~W} /(\mathrm{m} \cdot \mathrm{K})$, while the estimated $R_{b}$ is larger than the corresponding reference value of $0.162 \mathrm{~m} \cdot \mathrm{K} / \mathrm{W}$. The uncertainties of $\lambda_{e f f}$ and $R_{b}$ based on the $95 \%$ credible interval and the PM are $5.4 \%$ and 3.7\%, respectively. The point estimate and $95 \%$ credible interval of $r_{\sigma}$ afford good insight into the relative deviation between the measured temperature and that estimated by the forward model. 
Table 2. Estimations obtained by the deterministic method and Bayesian inference (PM: posterior mean, MAP: maximum a posteriori, $\mathrm{CI}$ : credible interval.)

\begin{tabular}{lllllc}
\hline Parameter [unit] & $\begin{array}{l}\text { Deterministic } \\
\text { (clean data) }\end{array}$ & $\begin{array}{l}\text { Deterministic } \\
\text { (noisy data) }\end{array}$ & Bayesian PM & Bayesian MAP & 95\% CI \\
\hline $\begin{array}{l}\text { Effective thermal } \\
\text { conductivity }[\mathrm{W} /(\mathrm{m} \cdot \mathrm{K}) \text { ] }\end{array}$ & 1.780 & 1.802 & 1.770 & 1.772 & $1.678-1.861$ \\
\hline $\begin{array}{l}\text { Borehole thermal } \\
\text { resistance }[\mathrm{m} \cdot \mathrm{K} / \mathrm{W}]\end{array}$ & 0.162 & 0.169 & 0.164 & 0.165 & $0.158-0.170$ \\
\hline Error ratio [\%] & N/A & N/A & 1.15 & 1.14 & $0.96-1.40$ \\
\hline
\end{tabular}

Using the $95 \% \mathrm{CI}$ of the parameters and the points estimated from the PM, the temperature response was reproduced by the forward model, as shown in Fig. 7. Because the temperature data from $14 \mathrm{~h}$ onward was used for the estimation, only the temperatures for 14-72 h are plotted. The temperature response obtained from the PM can be observed to pass through the center of the fluctuating measured temperature. Additionally, the temperature range for the $95 \% \mathrm{CI}$ encloses all the fluctuating temperature data. This indicates that the fluctuation of the temperature response due to random errors and the resulting uncertainties of the parameters are all considered within the $95 \%$ CI estimated by the Bayesian inference.

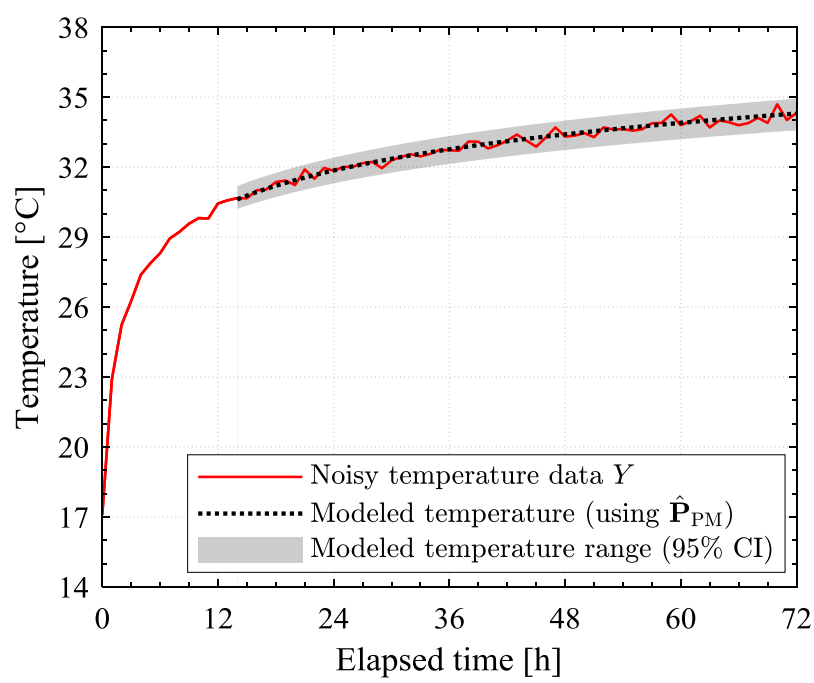

Fig. 7. Noisy temperature response data used for Bayesian inference, temperature response modeled using point estimates based on the posterior mean, and upper and lower bounds of the temperature modeled using the $95 \%$ credible intervals of the estimates.

Another advantage of the Bayesian approach is its ability to yield a joint distribution when two or more parameters are simultaneously estimated. The joint distribution of the PPDFs of $\lambda_{e f f}$ and $R_{b}$ shown in Fig. 5 was created as shown in Fig. 8. From the joint distribution, the correlation of the two parameters can be determined, as well as the area where the most reliable pairs of parameters exist. A positive correlation between the two parameters is evident from the figure, and the yellow area defines the most reliable pairs of $\lambda_{e f f}$ and $R_{b}$. These advantages of the stochastic estimation method can be exploited to account for the risk arising from incorrect TRT estimation in the design of the GSHP.

Using the reference sandbox TRT dataset [63], additional verification of proposed method was conducted, and is provided in Appendix B. 


\section{Application to in situ TRT data: relationship between TRT duration and estimation uncertainty}

The Bayesian inference approach validated in Section 4 was applied to in situ TRT data. Based on the estimations obtained using the in situ TRT data, two things could be clarified. Firstly, the amount of uncertainty that exists when using in situ TRT data can be determined. This includes the uncertainty caused by many other disturbance factors apart from the random error of the sensors, such as heat exchange between the outdoor environment, the aboveground TRT setup, and voltage fluctuation. Secondly, the variation of the estimation uncertainty with the TRT duration can be determined.

The TRT data was obtained using the experimental setup described in Ref. [76]. The geometry of the BHE was the same as that of the numerical model (see Table 1). The BHE was a 50-m long single U-tube, and was inserted into a borehole of diameter $165 \mathrm{~mm}$. The annulus was grouted using Portland cement mixed with silica sand. The ground formation at the site mainly consisted of fine sand. The TRT was conducted for $96 \mathrm{~h}$. The experimental conditions are listed in Table 3. The temperature response and heat injection rate are shown in Fig. 9 (a), while the dry-bulb temperature and global horizontal irradiance are shown in Fig. 9 (b).

The uncertainties of the installed Pt-100 sensor and flowmeter, as provided by the manufacturers, were respectively $\pm(0.15+(0.002 \cdot T))\left[{ }^{\circ} \mathrm{C}\right]$ and $\pm 0.006 \cdot \dot{V}$, which are the same as the random errors applied to the numerical TRT data. However, because the sensors were well calibrated, the actual random errors were much smaller than the specifications. As can be seen from the temperature response in Fig. 9 (a), the random errors are not evident compared with the case of the numerical data in Fig. 1; rather, the effect of the heat exchange between the aboveground setup and the external environment is more prominent. As was shown in Refs. [37,38], the disturbed heat exchange rate between the TRT setup and the external environment is the most sensitive to radiant heat transfer, for which reason the largest disturbed heat exchange rate occurs in summer. Because the TRT was conducted in summer when the global solar irradiance is close to $1000 \mathrm{~W} / \mathrm{m}^{2}$ (Fig. 9 (b)), the effect of the disturbed heat exchange rate was evident from the measured temperature response and heat exchange rate (Fig. 9 (a)) 
Table 3. Experimental conditions of the in situ TRT. ( $\bar{q}$ : average heat rate, $\sigma$ : standard deviation, $\dot{V}$ : volumetric flow rate, $T_{0}$ : initial ground temperature.)

\begin{tabular}{lccccc}
\hline Start time & $\begin{array}{c}\text { Duration } \\
{[\mathrm{h}]}\end{array}$ & $\begin{array}{c}\bar{q} \\
{[\mathrm{~W} / \mathrm{m}]}\end{array}$ & $\begin{array}{c}\sigma \text { of } \bar{q} \\
{[\mathrm{~W} / \mathrm{m}]([\mathrm{W}])}\end{array}$ & $\begin{array}{c}\dot{V} \\
{[\mathrm{~L} / \mathrm{min}]}\end{array}$ & $\begin{array}{c}T_{0} \\
{\left[{ }^{\circ} \mathrm{C}\right]}\end{array}$ \\
\hline 23:00, July 9, 2015 & 96 & 46.00 & $1.36(68)$ & 20.13 & 17.27 \\
\hline
\end{tabular}
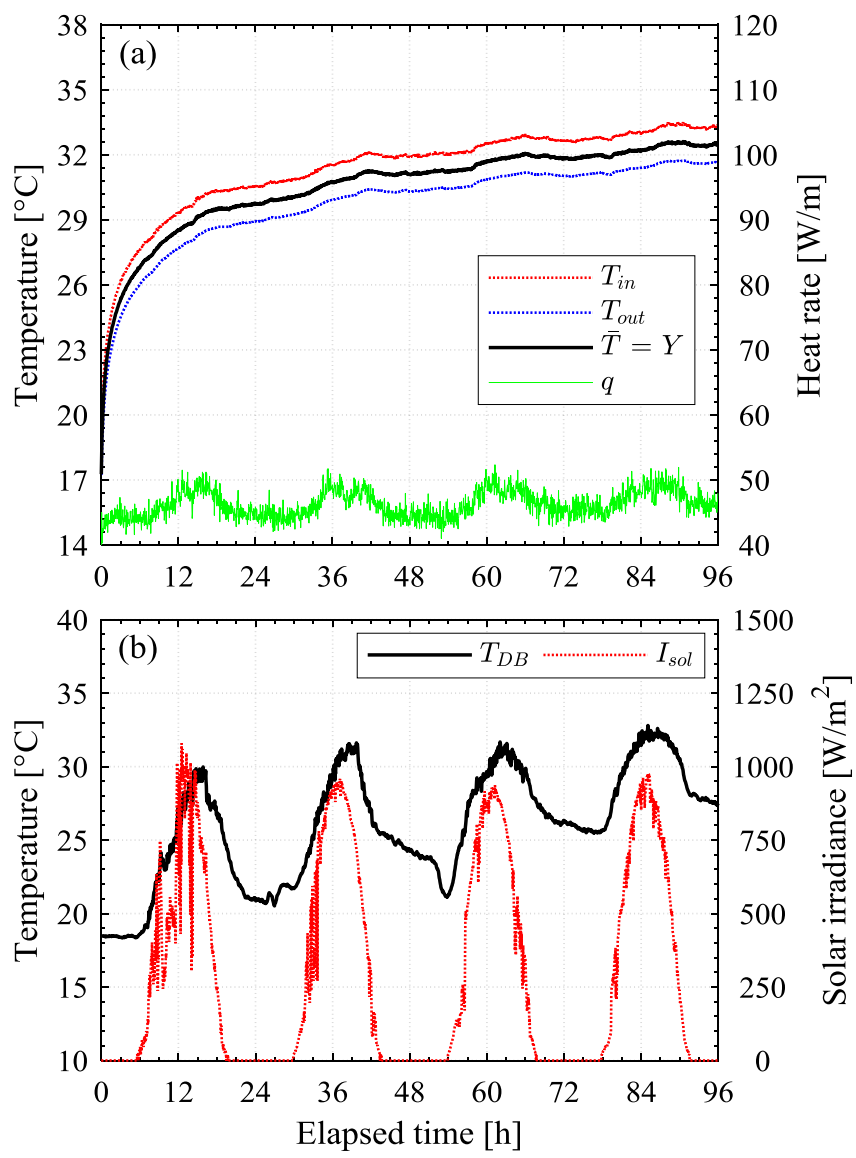

Fig. 9. In situ thermal response test results and weather data: (a) temperature response and heat injection rate, and (b) dry-bulb temperature $T_{D B}$ and global solar irradiance $I_{s o l}$ ).

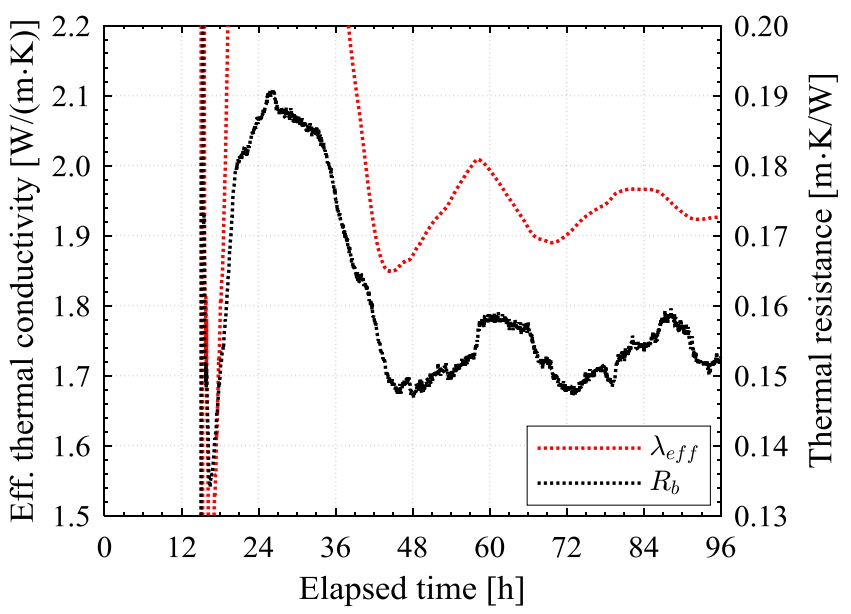

Fig. 10. Sequential estimations obtained using the simplified infinite line source model.

Fig. 10 shows the results of the sequential estimations (deterministic estimations) using the simplified ILS model. The mean temperature data for elapsed time from $14 \mathrm{~h}$ onward was used for the estimation. Compared with sequential estimation using numerical TRT data shown in Fig. 2, the estimation fluctuated at a larger amplitude. Moreover, rather 
than high-frequency oscillation caused by the random error of sensors, a low-frequency oscillation with a daily cycle was distribution (Fig. 8).

As different estimation behaviors by the in situ and the numerical TRT data (i.e., data containing the combination of measurement and contextual errors, and those containing only the measurement) were observed, we wanted to quantify the difference in uncertainty as outdoor disturbance was added to the measurement error. In addition to examining the influence of outdoor disturbance on the parameters, as described in Section 1, the main objective of this exercise was to determine the appropriate minimum duration of the TRT. Beginning with the minimum TRT time of $36 \mathrm{~h}$ recommended by ASHRAE (i.e., using data for 14-36 h), the end time was increased in steps of six hours. A total of 11 and seven cases of estimations for the in situ TRT and the numerical TRT (used in Section 4), respectively, were thus considered, as reported in Table 4 and Table 5. Using the results of in situ TRT data, we propose an optimum minimum duration of TRT based on two criteria: (a) whether the posterior mean was within a 95\% CI range using all data (96 h and $72 \mathrm{~h}$ for in situ TRT and numerical TRT, respectively), and (b) the reduction of the range of uncertainty around the mean value.

It should be noted that the comparison between Table 4 and Table 5 is meaningful only for the magnitude of uncertainty because the TRT conditions were different between them. Therefore, the results using numerical TRT data were only used to compare the magnitudes of uncertainty subjected to different sources of error.

With the aid of the Metropolis-Hastings algorithm, $5 \times 10^{5}$ samplings were used to draw the PPDFs, having omitted the first $1 \times 10^{5}$ samplings. From the PPDFs of $\lambda_{e f f}$ and $R_{b}$, the posterior mean, $95 \%$ credible interval, and percentage uncertainty were extracted (see Table 4 and Table 5). In the calculation of percentage uncertainty, the denominator in Eq. (28) was fixed to the PM for a duration of $96 \mathrm{~h}$ (case E96) and $72 \mathrm{~h}$ (case N72) for in situ TRT and numerical TRT, respectively. The box plots for $\lambda_{e f f}$ and $R_{b}$ using the experimental data are shown in Fig. 11.

It is generally known that reliability of estimates increases as TRT time increases. Therefore, we set the $95 \%$ CI of $\lambda_{\text {eff }}$ and $R_{b}$ in case E96, namely, $\lambda_{\text {eff }}=1.86-1.99 \mathrm{~W} /(\mathrm{m} \cdot \mathrm{K})$ and $R_{b}=0.144-0.152 \mathrm{~m} \cdot \mathrm{K} / \mathrm{W}$, respectively, as plausible ranges of estimation and used them as a standard for comparison.
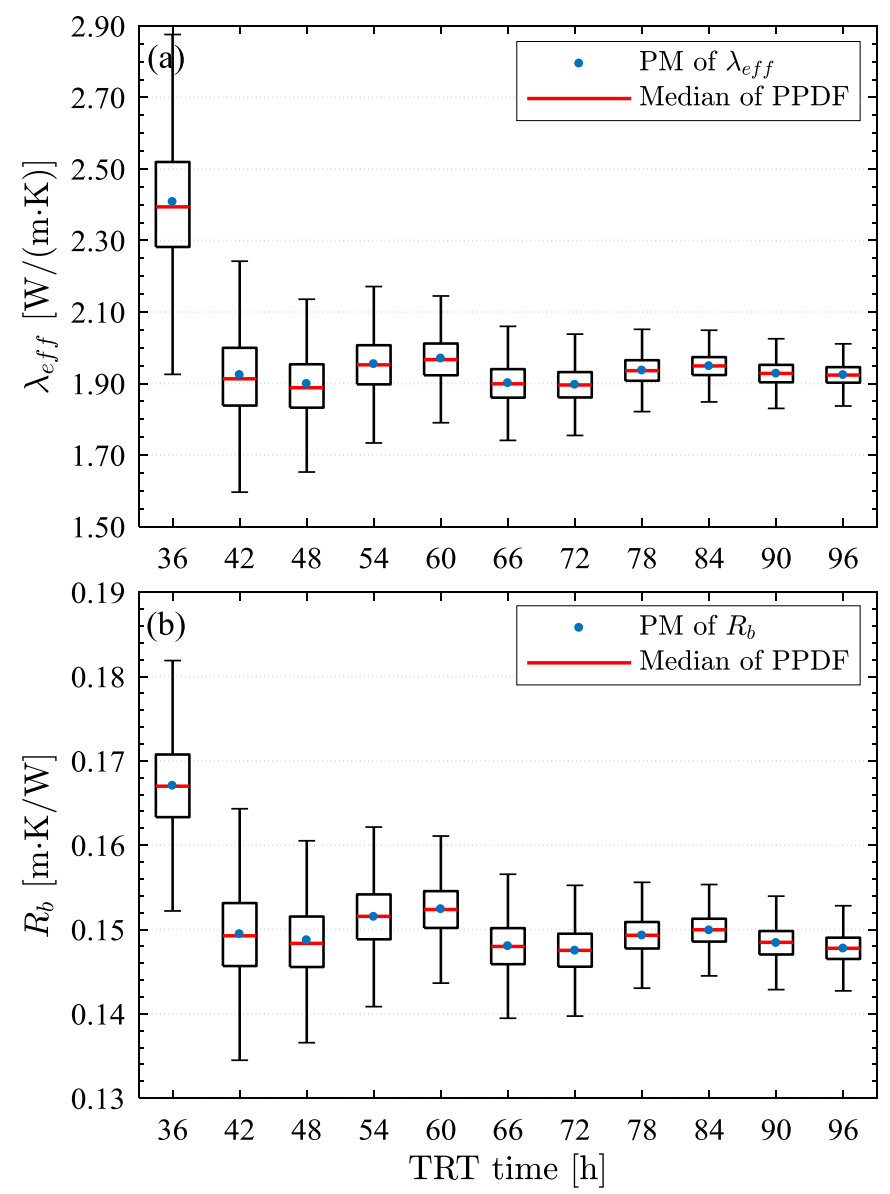

Fig. 11. Box plots of the estimated effective thermal conductivity and borehole thermal resistance using in situ TRT 
data.

Table 4. Variations of the posterior mean, 95\% credible interval, and estimation uncertainties with the TRT duration (in situ TRT data).

\begin{tabular}{|c|c|c|c|c|c|c|c|}
\hline \multirow[t]{2}{*}{ Case } & \multirow{2}{*}{$\begin{array}{c}\text { Test duration } \\
\text { of data [h] }\end{array}$} & \multicolumn{3}{|c|}{ Effective thermal conductivity } & \multicolumn{3}{|c|}{ Borehole thermal resistance } \\
\hline & & $\begin{array}{c}\mathrm{PM} \\
{[\mathrm{W} /(\mathrm{m} \cdot \mathrm{K})]}\end{array}$ & $\begin{array}{c}95 \% \text { CI } \\
{[\mathrm{W} /(\mathrm{m} \cdot \mathrm{K})]}\end{array}$ & $\begin{array}{c}\text { Uncertainty } \\
{[\%]}\end{array}$ & $\begin{array}{c}\mathrm{PM} \\
{[\mathrm{m} \cdot \mathrm{K} / \mathrm{W}]}\end{array}$ & $\begin{array}{c}95 \% \mathrm{CI} \\
{[\mathrm{m} \cdot \mathrm{K} / \mathrm{W}]}\end{array}$ & $\begin{array}{c}\text { Uncertainty } \\
{[\%]}\end{array}$ \\
\hline E36 & $14-36$ & 2.42 & $2.10-2.90$ & 20.7 & 0.167 & $0.157-0.181$ & 8.0 \\
\hline E42 & $14-42$ & 1.93 & $1.70-2.21$ & 13.3 & 0.150 & $0.138-0.162$ & 7.9 \\
\hline E48 & $14-48$ & 1.90 & $1.73-2.12$ & 10.0 & 0.149 & $0.140-0.159$ & 6.3 \\
\hline E54 & $14-54$ & 1.95 & $1.80-2.12$ & 8.3 & 0.151 & $0.144-0.159$ & 5.2 \\
\hline E60 & $14-60$ & 1.97 & $1.84-2.11$ & 7.0 & 0.152 & $0.146-0.159$ & 4.5 \\
\hline E66 & $14-66$ & 1.90 & $1.79-2.02$ & 5.9 & 0.148 & $0.142-0.154$ & 4.1 \\
\hline E72 & $14-72$ & 1.90 & $1.80-2.00$ & 5.2 & 0.147 & $0.142-0.153$ & 3.7 \\
\hline E78 & $14-78$ & 1.94 & $1.85-2.03$ & 4.6 & 0.149 & $0.145-0.154$ & 3.2 \\
\hline E84 & $14-84$ & 1.95 & $1.87-2.03$ & 4.1 & 0.150 & $0.146-0.154$ & 2.9 \\
\hline E90 & $14-90$ & 1.93 & $1.86-2.00$ & 3.7 & 0.148 & $0.144-0.152$ & 2.8 \\
\hline E96 & $14-96$ & 1.92 & $1.86-1.99$ & 3.4 & 0.148 & $0.144-0.152$ & 2.6 \\
\hline
\end{tabular}

Table 5. Variations in the posterior mean, $95 \%$ credible interval, and estimation uncertainties with the TRT duration (numerical TRT data).

\begin{tabular}{|c|c|c|c|c|c|c|c|}
\hline \multirow[t]{2}{*}{ Case } & \multirow{2}{*}{$\begin{array}{l}\text { Test duration } \\
\text { of data }[\mathrm{h}]\end{array}$} & \multicolumn{3}{|c|}{ Effective thermal conductivity } & \multicolumn{3}{|c|}{ Borehole thermal resistance } \\
\hline & & $\begin{array}{l}\mathrm{PM} \\
{[\mathrm{W} /(\mathrm{m} \cdot \mathrm{K})]}\end{array}$ & $\begin{array}{l}95 \% \mathrm{CI} \\
{[\mathrm{W} /(\mathrm{m} \cdot \mathrm{K})]}\end{array}$ & $\begin{array}{l}\text { Uncertainty } \\
{[\%]}\end{array}$ & $\begin{array}{l}\mathrm{PM} \\
{[\mathrm{m} \cdot \mathrm{K} / \mathrm{W}]}\end{array}$ & $\begin{array}{l}95 \% \mathrm{CI} \\
{[\mathrm{m} \cdot \mathrm{K} / \mathrm{W}]}\end{array}$ & $\begin{array}{l}\text { Uncertainty } \\
{[\%]}\end{array}$ \\
\hline N36 & $14-36$ & 1.92 & $2.25-1.67$ & 16.2 & 0.174 & $0.163-0.188$ & 7.6 \\
\hline $\mathrm{N} 42$ & $14-42$ & 1.81 & $1.63-2.03$ & 11.1 & 0.169 & $0.160-0.180$ & 6.0 \\
\hline $\mathrm{N} 48$ & $14-48$ & 1.78 & $1.65-1.96$ & 8.7 & 0.169 & $0.161-0.177$ & 5.0 \\
\hline N54 & $14-54$ & 1.79 & $1.66-1.91$ & 7.2 & 0.168 & $0.161-0.176$ & 4.3 \\
\hline N60 & $14-60$ & 1.77 & $1.66-1.89$ & 6.3 & 0.168 & $0.161-0.174$ & 4.0 \\
\hline N66 & $14-66$ & 1.75 & $1.66-1.86$ & 5.6 & 0.166 & $0.160-0.172$ & 3.7 \\
\hline N72 & $14-72$ & 1.77 & $1.68-1.86$ & 5.1 & 0.164 & $0.158-0.170$ & 3.7 \\
\hline
\end{tabular}

As shown in Table 4, the PMs and the $95 \% \mathrm{CI}$ of $\lambda_{\text {eff }}$ and $R_{b}$ for case E36, which had the shortest TRT time, had completely deviating values from those of other cases, where the values were outside the plausible ranges. E36 had the largest uncertainty of $\lambda_{e f f}$ and $R_{b}$, which were $20.7 \%$ and $8.0 \%$, respectively. The relatively low uncertainty of $R_{b}$ compared with that of $\lambda_{\text {eff }}$ owed to the higher sensitivity of $R_{b}$ to temperature response in the general time frame of TRTs with a duration of less than $100 \mathrm{~h}$, especially during the early period in the first $50 \mathrm{~h}$. The variations in the transient sensitivity coefficients of the two parameters are discussed in detail in Ref. [76].

From E42 onward, the point estimates based on the PM were within the plausible estimation ranges, but uncertainty remained high. In case E48, although the uncertainty of $\lambda_{\text {eff }}$ was still higher than $10 \%$, it was approximately $50 \%$ less than that of E36. As can be observed from Fig. 11 and Fig. 12, the estimation uncertainty decreased exponentially as TRT time increased. This was consistent with the results in Ref. [76], where a statistical analysis of 36 cases of numerical TRTs was conducted by considering the disturbance of an aboveground TRT setup. From case E54 (test duration of $54 \mathrm{~h}$ ) onward, the uncertainty of $\lambda_{\text {eff }}$ was below $10 \%$, dropping to below $5 \%$ for case E78, and further to $\sim 3.5 \%$ for case E96. The uncertainty of $R_{b}$ also decreased exponentially with increasing test duration, falling to $\sim 2.6 \%$ for case E96. 


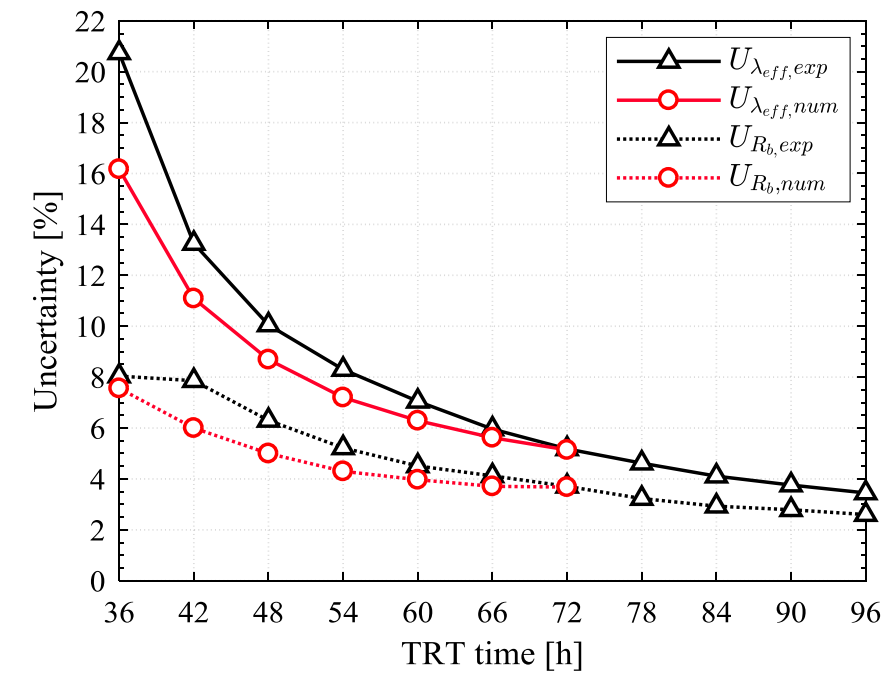

Fig. 12. Uncertainty comparison between in situ and numerical TRT data (subscript exp represents in situ TRT data, and num represents numerically generated TRT data).

Fig. 12 shows the variation in estimated uncertainties using experimental and numerical TRT data with time (Table 4 and Table 5). Overall, the estimated uncertainties using experimental data were larger than those using numerical data. In particular, when the TRT time was short, the difference tended to be large, and gradually decreases with time. Therefore, the contextual disturbances (i.e., disturbance from the outdoor environment, voltage fluctuation, etc.) were found to have a greater impact on the estimation when the TRT time was shorter. This is a natural consequence, considering that the relative temperature perturbation is more sensitive to the same magnitude of disturbance when fluid temperature is lower.

Interestingly, the estimation uncertainties for case E72 are very close to those of N72. This is despite other disturbance factors such as the heat exchange in the aboveground setup and the output fluctuation of the heater being considered in the experiments, in addition to the random error of the sensors. To explain this similarity, we refer to Ref. [37], in which the magnitude of the disturbed heat exchange rate in the aboveground TRT setup was numerically analyzed. In this previous work, a heat gain rate (heat transfer rate from the outdoor environment to the circulating fluid) of approximately $80 \mathrm{~W}$ was determined for a dry-bulb temperature of $34{ }^{\circ} \mathrm{C}$, global solar irradiance of $1000 \mathrm{~W} / \mathrm{m}^{2}$, wind speed of $0.5 \mathrm{~m} / \mathrm{s}$, BHE outlet temperature of $30^{\circ} \mathrm{C}$, and connection circuit length of $2 \mathrm{~m}$ (from the BHE to the TRT apparatus). These conditions are very close to the weather conditions during the TRT data shown in Fig. 9. In the case of nighttime, because the temperature of the circulating fluid is higher than the outdoor temperature (Fig. 9), heat is released from the fluid to the atmosphere. This diurnal change under outdoor conditions produces a low-frequency periodicity in $q$. The heat rate $q$ is also affected by the fluctuation of the supply voltage and the random errors of the sensors. The fluctuation of the supply voltage and the random errors of the sensors generate high-frequency noise, as shown in Fig. 9 (a). The standard deviation $\sigma$ of $q$ obtained from the experimental results is $68 \mathrm{~W}(1.36 \mathrm{~W} / \mathrm{m}$ in Table 3). For a confidence interval of $2 \sigma$, which covers the $95.45 \%$ data range of $q$, the standard deviation is $136 \mathrm{~W}$. This amplitude of $136 \mathrm{~W}$ produces a temperature fluctuation of $\sim 0.1^{\circ} \mathrm{C}$ for an average flow rate of $20.13 \mathrm{~L} / \mathrm{min}$ (Table 3 ). This temperature fluctuation amplitude is close to that of the numerical TRT data, confirming the reasonableness of the comparable experimentally and numerically determined uncertainties for a test duration of $72 \mathrm{~h}$.

To summarize, there are several opinions regarding the minimum TRT duration from a deterministic point of view, but the absolute true parameter values cannot be determined for an in situ TRT. The minimum TRT time should therefore be examined with the objective of minimizing the uncertainties. The results for case E54 are within an uncertainty range of $\pm 8.3 \%$, which is better than the generally acceptable uncertainty range of $\pm 10 \%$. Therefore, based on the experimental data of this study, we recommend a minimum TRT duration of $50 \mathrm{~h}$. Of course, depending on the TRT setup and conditions, the uncertainty range for this minimum test duration may vary from those of the present experiment. Various conditions should therefore be considered for the minimum duration of the TRT. Ideally, Bayesian inference must be carried out in a real-time manner until uncertainties in parameter estimates falls within an acceptable range of uncertainty. By doing so, TRTs can be conducted in a time- and cost-effective manner without losing confidence in the estimated parameters. The proposed estimation method can facilitate the design of reliable ground heat exchangers with reduced operational risks. 


\section{Conclusions}

In this study, we developed a stochastic parameter estimation method based on Bayes' theorem. The use of the conventional deterministic estimation method could lead to erroneous design. The Bayesian inference approach proposed in this paper not only produces the point estimates, but also the credible intervals of the parameters. This promises to facilitate the design of reliable ground heat exchangers with reduced operational risks. To verify the proposed method by comparison of its results with known true values, numerical TRT data was generated using the FEM, and additive random sensor errors were applied to the data. Using the Metropolis-Hastings sampling algorithm, the PPDFs of the effective thermal conductivity, borehole thermal resistance, and error ratio between the measured and modeled temperatures were derived. From the PPDFs, the point estimates and their 95\% credible intervals were extracted. The point estimates were found to be very close to the set values of the numerical model. The joint distribution of the effective thermal conductivity and borehole thermal resistance was also derived, and could be used for intuitive determination of the correlation between the two parameters for their simultaneous estimation and assessment of the uncertainty range.

In addition, to examine the relationship between the TRT time and the estimation uncertainty, the proposed stochastic estimation method was applied to in situ TRT data. The results obtained using the minimum test time of $36 \mathrm{~h}$ recommended by ASHRAE was found to significantly deviate from the plausible parameter range, with the estimation uncertainty of the effective thermal conductivity being $\sim 21 \%$. The uncertainty was, however, found to decrease exponentially with increasing test time, with the estimation uncertainty of the effective thermal conductivity dropping to below $10 \%$ for a test time of $\sim 50 \mathrm{~h}$. Based on the observations, we suggest a minimum TRT time of $50 \mathrm{~h}$. A longer TRT duration would increase the estimation accuracy, and considering the exponential decrease of the uncertainty with the TRT time, $72 \mathrm{~h}$ is expected to produce sufficiently accurate estimates for most cases.

Although, we mentioned the minimum TRT time of $50 \mathrm{~h}$ based on this study, fixing a standard duration of TRT time is not reasonable because (1) the configurations of the ground heat exchanger are different in each TRT, (2) the intensity of the contextual disturbance during a TRT is different, and (3) the parameter estimation methods are different. The propose method allows experimenters to stop a TRT with rational basis for estimation accuracy and uncertainty. The advantages of developed method will be maximized if real-time estimates during a TRT are conducted at regular intervals until uncertainty ranges are within acceptable limits.

Although this study proposed a methodology for the estimation of TRT-related parameters, it is based on the assumption that all measurement and model errors are random. This is a reasonable assumption for this study because our numerical problem is exceptionally well defined, and our measurement data is synthetically generated. However, in a real TRT setup, errors arising from systematic bias in model and measurements must also be included. To do so, one must apply expert judgement on prior estimates of systematic errors, including their structure and magnitude. Although such systematic errors can be partially considered by the confidence interval of the estimated parameter, without an explicit consideration, there is a high possibility of overfitting the problem, especially when the physical model cannot represent the temperature response adequately. Future work must extend this framework to quantify them explicitly. Doing so can significantly optimize the duration of the TRT test by reducing uncertainties in estimated parameters.

\section{Acknowledgments}

This work was supported by the Japan Society for the Promotion of Science (JSPS) (KAKENHI, grant numbers 26709041 and P16074).

\section{References}

[1] Lee CK. Effects of multiple ground layers on thermal response test analysis and ground-source heat pump simulation. Applied Energy 2011;88:4405-10. doi:10.1016/j.apenergy.2011.05.023.

[2] Bernier M. Uncertainty in the design length calculation for vertical ground heat exchangers. ASHRAE Transactions 2002;108:939-44.

[3] Kavanaugh SP, Rafferty KD. Ground-source heat pumps: Design of geothermal systems for commercial and institutional buildings. Atlanta: ASHRAE; 1997.

[4] ASHRAE. ASHRAE Handbook - HVAC Applications, Chapter 34. Atlanta, GA: American Society of Heating, Refrigerating and Air-Conditioning Engineers Inc.; 2015.

[5] Robert F, Gosselin L. New methodology to design ground coupled heat pump systems based on total cost minimization. Applied Thermal Engineering 2014;62:481-91. doi:10.1016/j.applthermaleng.2013.08.003. 
[6] Mogensen P. Fluid to duct wall heat transfer in duct system heat storages. Proceedings of International Conference on Subsurface Heat Storage in Theory and Practice, Stockholm, Sweden: Swedish Council for Building Research; 1983, p. 652-7.

[7] Eklöf C, Gehlin S. TED—a mobile equipment for thermal response tests. Lulea University of Technology, 1996.

[8] Gehlin S. Thermal response test: method development and evaluation. Lulea University of Technology, 2002.

[9] Ingersoll LR, Zobel OJ, Ingersoll AC. Heat conduction with engineering, geological, and other applications. Madison: University of Wisconsin Press; 1954.

[10] Carslaw HS, Jaeger JC. Conduction of Heat in Solids. 2nd ed. UK: Oxford University Press; 1959.

[11] Fujii H, Okubo H, Nishi K, Itoi R, Ohyama K, Shibata K. An improved thermal response test for Utube ground heat exchanger based on optical fiber thermometers. Geothermics 2009;38:399-406. doi:10.1016/j.geothermics.2009.06.002.

[12] Austin WAI. Development of an in situ system for measuring ground thermal properties. Oklahoma State University, 1998.

[13] Chiasson AD, O'Connell A. New analytical solution for sizing vertical borehole ground heat exchangers in environments with significant groundwater flow: Parameter estimation from thermal response test data. HVAC\&R Research 2011;17:1000-11. doi:10.1080/10789669.2011.609926.

[14] Wagner V, Blum P, Kübert M, Bayer P. Analytical approach to groundwater-influenced thermal response tests of grouted borehole heat exchangers. Geothermics 2013;46:22-31. doi:10.1016/j.geothermics.2012.10.005.

[15] Yu X, Zhang Y, Deng N, Wang J, Zhang D, Wang J. Thermal response test and numerical analysis based on two models for ground-source heat pump system. Energy and Buildings 2013;66:657-66. doi:10.1016/j.enbuild.2013.07.074.

[16] Nelder JA, Mead R. A simplex method for function minimization. The Computer Journal 1965;7:308-13. doi:10.1093/comjnl/7.4.308.

[17] Li M, Lai ACK. Parameter estimation of in situ thermal response tests for borehole ground heat exchangers. International Journal of Heat and Mass Transfer 2012;55:2615-24. doi:http://dx.doi.org/10.1016/j.ijheatmasstransfer.2011.12.033.

[18] More JJ. The Levenberg-Marquardt algorithm: Implementation and theory. Lecture Notes in Mathematics 1978;630:105-16. doi:10.1007/BFb0067700.

[19] Levenberg K. A Method for the Solution of Certain Non-linear Problems in Least Squares. Quarterly of Applied Mathematics 1944;2:164-8.

[20] Marquardt DW. An Algorithm for Least-Squares Estimation of Nonlinear Parameters. Journal of the Society for Industrial and Applied Mathematics 1963;11:431-41. doi:10.1137/0111030.

[21] Choi W, Ooka R. Interpretation of disturbed data in thermal response tests using the infinite line source model and numerical parameter estimation method. Applied Energy 2015;148:476-88. doi:10.1016/j.apenergy.2015.03.097.

[22] Broyden CG. . The convergence of a class of double-rank minimization algorithms 1: General considerations. IMA Journal of Applied Mathematics 1970;6:76-90. doi:10.1093/imamat/6.1.76.

[23] Fletcher R. A new approach to variable metric algorithms. The Computer Journal 1970;13:317-22. doi:10.1093/comjnl/13.3.317.

[24] Goldfarb D. A family of variable-metric methods derived by variational means. Mathematics of Computation 1970;24:23-6. doi:10.1090/S0025-5718-1970-0258249-6.

[25] Shanno DF. Conditioning of quasi-Newton methods for function minimization. Mathematics of Computation 1970;24:647-56. doi:10.1090/S0025-5718-1970-0274029-X.

[26] Bozzoli F, Pagliarini G, Rainieri S, Schiavi L. Estimation of soil and grout thermal properties through a TSPEP (two-step parameter estimation procedure) applied to TRT (thermal response test) data. Energy 2011;36:839-46. doi:10.1016/j.energy.2010.12.031.

[27] Beck J, Arnold KJ. Parameter estimation in engineering and science. New York: Wiley Interscience; 1977.

[28] Shonder JA, Beck J. Field test of a new method for determining soil formation thermal conductivity and borehole resistance. ASHRAE Transactions 2000;106:843-50.

[29] Roth P, Georgiev A, Busso A, Barraza E. First in situ determination of ground and borehole thermal properties in Latin America. Renewable Energy 2004;29:1947-63. doi:10.1016/j.renene.2004.02.014.

[30] Sharqawy MH, Said SA, Mokheimer EM, Habib MA, Badr HM, Al-Shayea NA. First in situ determination of the ground thermal conductivity for boreholeheat exchanger applications in Saudi Arabia. Renewable Energy 2009;34:2218-23. doi:10.1016/j.renene.2009.03.003.

[31] Hu P, Meng Q, Sun Q, Zhu N, Guan C. A method and case study of thermal response test with unstable heat rate. Energy and Buildings 2012;48:199-205. doi:10.1016/j.enbuild.2012.01.036. 
[32] Zhang C, Song W, Sun S, Peng D. Parameter estimation of in situ thermal response test with unstable heat rate. Energy 2015;88:497-505. doi:10.1016/j.energy.2015.05.074.

[33] Bandos T V, Montero Á, Fernández de Córdoba P, Urchueguía JF. Improving parameter estimates obtained from thermal response tests: Effect of ambient air temperature variations. Geothermics 2011;40:136-43. doi:10.1016/j.geothermics.2011.02.003.

[34] Signorelli S, Bassetti S, Pahud D, Kohl T. Numerical evaluation of thermal response tests. Geothermics 2007;36:141-66. doi:10.1016/j.geothermics.2006.10.006.

[35] Borinaga-Treviño R, Norambuena-Contreras J, Castro-Fresno D. How to correct the ambient temperature influence on the thermal response test results. Applied Thermal Engineering 2015;82:39-47. doi:10.1016/j.applthermaleng.2015.02.050.

[36] Abdelaziz SL, Olgun CG, Martin JR. Counterbalancing ambient interference on thermal conductivity tests for energy piles. Geothermics 2015;56:45-59. doi:10.1016/j.geothermics.2015.03.005.

[37] Choi W, Ooka R. Effect of disturbance on thermal response test, part 1: Development of disturbance analytical model, parametric study, and sensitivity analysis. Renewable Energy 2016;85:306-18. doi:10.1016/j.renene.2015.06.042.

[38] Choi W, Ooka R. Effect of disturbance on thermal response test, part 2: Numerical study of applicability and limitation of infinite line source model for interpretation under disturbance from outdoor environment. Renewable Energy 2016;85:1090-105. doi:10.1016/j.renene.2015.07.049.

[39] ISO. Guide to the Expression of Uncertainty in Measurement. Geneva, Switzerland: International Organization for Standardization; 1995.

[40] Sharqawy MH, Mokheimer EM, Habib MA, Badr HM, Said SA, Al-Shayea NA. Energy, exergy and uncertainty analyses of the thermal response test for a ground heat exchanger. International Journal of Energy Research 2009;33:582-92. doi:10.1002/er.1496.

[41] Raymond J, Therrien R, Gosselin L, Lefebvre R. A Review of Thermal Response Test Analysis Using Pumping Test Concepts. Ground Water 2011;49:932-45. doi:10.1111/j.1745-6584.2010.00791.x.

[42] Underwood C. Ground source heat pumps: observations from United Kingdom ground thermal response tests. Building Services Engineering Research and Technology 2013;34:123-44. doi:10.1177/0143624411424467.

[43] Raymond J, Lamarche L, Malo M. Field demonstration of a first thermal response test with a low power source. Applied Energy 2015;147:30-9. doi:10.1016/j.apenergy.2015.01.117.

[44] Spitler JD, Javed S, Ramstad RK. Natural convection in groundwater-filled boreholes used as ground heat exchangers. Applied Energy 2016;164:352-65. doi:10.1016/j.apenergy.2015.11.041.

[45] Cimmino M, Bernier M. Experimental determination of the g-functions of a small-scale geothermal borehole. Geothermics 2015;56:60-71. doi:10.1016/j.geothermics.2015.03.006.

[46] Witte HJL. Error analysis of thermal response tests. Applied Energy 2013;109:302-11. doi:10.1016/j.apenergy.2012.11.060.

[47] Shang Y, Dong M, Li S. Intermittent experimental study of a vertical ground source heat pump system. Applied Energy 2014;136:628-35. doi:10.1016/j.apenergy.2014.09.072.

[48] Wang J, Zabaras N. Hierarchical Bayesian models for inverse problems in heat conduction. Inverse Problems 2005;21:183-206. doi:10.1088/0266-5611/21/1/012.

[49] Parthasarathy S, Balaji C. Estimation of parameters in multi-mode heat transfer problems using Bayesian inference - Effect of noise and a priori. International Journal of Heat and Mass Transfer 2008;51:231334. doi:10.1016/j.ijheatmasstransfer.2007.08.031.

[50] Gori V, Marincioni V, Biddulph P, Elwell CA. Inferring the thermal resistance and effective thermal mass distribution of a wall from in situ measurements to characterise heat transfer at both the interior and exterior surfaces. Energy and Buildings 2017;135:398-409. doi:10.1016/j.enbuild.2016.10.043.

[51] Toivanen JM, Kolehmainen V, Tarvainen T, Orlande HRB, Kaipio JP. Simultaneous estimation of spatially distributed thermal conductivity, heat capacity and surface heat transfer coefficient in thermal tomography. International Journal of Heat and Mass Transfer 2012;55:7958-68. doi:10.1016/j.ijheatmasstransfer.2012.08.024.

[52] Gnanasekaran N, Balaji C. A Bayesian approach for the simultaneous estimation of surface heat transfer coefficient and thermal conductivity from steady state experiments on fins. International Journal of Heat and Mass Transfer 2011;54:3060-8. doi:10.1016/j.ijheatmasstransfer.2011.01.028.

[53] Chakraborty S, Das PK. Application of Bayesian Inference Technique for the reconstruction of an isothermal hot spot inside a circular disc from peripheral temperature measurement - A critical assessment. International Journal of Heat and Mass Transfer 2015;88:456-69. doi:10.1016/j.ijheatmasstransfer.2015.04.058.

[54] Li G, Shi J. Applications of Bayesian methods in wind energy conversion systems. Renewable Energy 2012;43:1-8. doi:10.1016/j.renene.2011.12.006.

[55] O'Neill PD. A tutorial introduction to Bayesian inference for stochastic epidemic models using Markov chain Monte Carlo methods. Mathematical Biosciences 2002;180:103-14. doi:10.1016/S0025- 
5564(02)00109-8

[56] Smith MD, Perry RL. In situ testing and thermal conductivity testing. Proceedings of the

Geoexchange Technical Conference and Exposition, Oklahoma State University, Stillwater, Oklahoma: 1999.

[57] Gehlin S, Hellström G. Comparison of four models for thermal response test evaluation. ASHRAE

Transactions 2003;109:131-42.

[58] Kavanaugh SP, Xie L, Martin C. Investigation of methods for determining soil and rock formation thermal properties from short-term field tests. Atlanta, Georgia: 2001.

[59] Austin WAI, Yavuzturk C, Spitler JD. Development of an in situ system and analysis procedure for measuring ground thermal properties. ASHRAE Transactions 2000;106:365-79.

[60] Javed S. Thermal response testing: Results and experiences from a ground source heat pump test facility with multiple boreholes. Proceedings of Clima 2013, Prague, Czech Republic: 2013.

[61] Liu YD, Beier RA. Required duration for borehole test validated by field data. ASHRAE Transactions 2009;115:782-92.

[62] Gehlin S. Thermal response test: in situ measurements of thermal properties in hard rock. Lulea University of Technology, 1998.

[63] Beier RA, Smith MD, Spitler JD. Reference data sets for vertical borehole ground heat exchanger models and thermal response test analysis. Geothermics 2011;40:79-85. doi:10.1016/j.geothermics.2010.12.007.

[64] Hagen G. Ueber die Bewegung des Wassers in engen cylindrischen Röhren. Annalen Der Physik Und Chemie 1839;122:423-42. doi:10.1002/andp.18391220304.

[65] Poiseuille JLM. Recherches expérimentales sur le mouvement des liquides dans les tubes de trèspetits diamètres. Comptes Rendus, Académie Des Sciences, Paris 1840;11:961-7.

[66] Poiseuille JLM. Recherches expérimentales sur le mouvement des liquides dans les tubes de trèspetits diamètres. Comptes Rendus, Académie Des Sciences, Paris 1841;12:112-5.

[67] Lamarche L, Kajl S, Beauchamp B. A review of methods to evaluate borehole thermal resistances in geothermal heat-pump systems. Geothermics 2010;39:187-200. doi:10.1016/j.geothermics.2010.03.003.

[68] Li M, Lai ACK. Review of analytical models for heat transfer by vertical ground heat exchangers (GHEs): A perspective of time and space scales. Applied Energy 2015;151:178-91.

doi:10.1016/j.apenergy.2015.04.070.

[69] Javed S, Spitler JD. Accuracy of borehole thermal resistance calculation methods for grouted single U-tube ground heat exchangers. Applied Energy 2017;187:790-806. doi:10.1016/j.apenergy.2016.11.079.

[70] Raymond J, Therrien R, Gosselin L. Borehole temperature evolution during thermal response tests. Geothermics 2011;40:69-78. doi:10.1016/j.geothermics.2010.12.002.

[71] Gamerman D, Lopes HF. Markov Chain Monte Carlo-Stochastic Simulation for Bayesian Inference. CRC Press; 2006.

[72] Congdon P. Applied Bayesian hierarchical methods. CRC Press; 2010.

[73] Metropolis N, Rosenbluth AW, Rosenbluth MN, Teller AH, Teller E. Equation of State Calculations by Fast Computing Machines. The Journal of Chemical Physics 1953;21:1087-92. doi:10.1063/1.1699114.

[74] Hastings WK. Monte Carlo sampling methods using Markov chains and their applications.

Biometrika 1970;57:97-109. doi:10.1093/biomet/57.1.97.

[75] Chib S, Greenberg E. Understanding the Metropolis-Hastings Algorithm. The American Statistician 1995;49:327. doi:10.2307/2684568.

[76] Choi W, Ooka R. Effect of natural convection on thermal response test conducted in saturated porous formation: Comparison of gravel-backfilled and cement-grouted borehole heat exchangers. Renewable Energy 2016;96:891-903. doi:10.1016/j.renene.2016.05.040.

[77] Beier RA. Transient heat transfer in a U-tube borehole heat exchanger. Applied Thermal Engineering 2014;62:256-66. doi:10.1016/j.applthermaleng.2013.09.014.

[78] Beier RA, Smith MD. Minimum duration of in situ tests on vertical boreholes. ASHRAE Transactions 2003; 109:475-86.

[79] Shonder JA, Beck J. Determining effective soil formation thermal properties from field data using a parameter estimation technique. ASHRAE Transactions 1999;105:458-66.

\section{Appendix. A Derivation of likelihood function}

This appendix presents the detailed derivation of the likelihood function in this paper, namely, the derivation of Eq. (17) from Eq. (16).

The likelihood functions with respect to the measured temperature and true temperature are expressed by Eqs. (14) and (15), respectively. Substituting these two equations into Eq. (16), the marginal likelihood function can be rewritten as follows: 
By completing the square for $\bar{T}_{t r}^{n}$, the above equation can be rewritten as follows:

$p(\mathbf{Y} \mid \mathbf{P})=\prod_{n=1}^{N} \frac{1}{2 \pi \sqrt{v_{y}^{n} v_{f}^{n}}} \int_{-\infty}^{\infty} \exp \left[-\frac{1}{2} \frac{v_{y}^{n}+v_{f}^{n}}{v_{y}^{n} v_{f}^{n}}\left\{\left(\bar{T}_{t r}^{n}-\frac{v_{f}^{n} Y^{n}+v_{y}^{n} F^{n}(\mathbf{P})}{v_{y}^{n}+v_{f}^{n}}\right)^{2}+\frac{v_{y}^{n} v_{f}^{n}}{\left(v_{y}^{n}+v_{f}^{n}\right)^{2}}\left(Y^{n}-F^{n}(\mathbf{P})\right)^{2}\right\}\right] \mathrm{d} \bar{T}_{t r}^{n}$

As can be seen, only the parts related to $\bar{T}_{t r}^{n}$ remain in the integral. Eq. (A2) can be rewritten as follows:

$p(\mathbf{Y} \mid \mathbf{P})=\prod_{n=1}^{N} \frac{1}{2 \pi \sqrt{v_{y}^{n} v_{f}^{n}}} \exp \left[-\frac{\left(Y^{n}-F^{n}(\mathbf{P})\right)^{2}}{2\left(v_{y}^{n}+v_{f}^{n}\right)}\right] \int_{-\infty}^{\infty} \exp \left[-\frac{1}{2} \frac{v_{y}^{n}+v_{f}^{n}}{v_{y}^{n} v_{f}^{n}}\left(\bar{T}_{t r}^{n}-\frac{v_{f}^{n} Y^{n}+v_{y}^{n} F^{n}(\mathbf{P})}{v_{y}^{n}+v_{f}^{n}}\right)^{2}\right] \mathrm{d} \bar{T}_{t r}^{n}$

The integral in Eq. (A3) has the form of the general integral of a Gaussian function, which is as follows:

$$
\int_{-\infty}^{\infty} e^{-a(x-b)^{2}} \mathrm{~d} x=\sqrt{\frac{\pi}{a}}
$$

Based on Eq. (A4), Eq. (A3) can be integrated with respect to $\bar{T}_{t r}^{n}$ and simplified as follows:

$$
\begin{aligned}
p(\mathbf{Y} \mid \mathbf{P}) & =\prod_{n=1}^{N} \frac{1}{2 \pi \sqrt{v_{y}^{n} v_{f}^{n}}} \exp \left[-\frac{\left(Y^{n}-F^{n}(\mathbf{P})\right)^{2}}{2\left(v_{y}^{n}+v_{f}^{n}\right)}\right] \sqrt{\frac{2 \pi v_{y}^{n} v_{f}^{n}}{v_{y}^{n}+v_{f}^{n}}} \\
= & \left(\prod_{n=1}^{N} \frac{1}{\sqrt{2 \pi\left(v_{y}^{n}+v_{f}^{n}\right)}}\right) \exp \left[-\frac{1}{2} \sum_{n=1}^{N} \frac{\left(Y^{n}-F^{n}(\mathbf{P})\right)^{2}}{v_{y}^{n}+v_{f}^{n}}\right]
\end{aligned}
$$

\section{Appendix. B Additional verification of Bayesian inference against reference sandbox TRT data [63]}

Most TRTs are carried out at construction sites, where many experimental conditions cannot be fully controlled. For verification purposes, such data cannot be used, which is why we applied Bayesian inference to the numerically generated TRT data in Section 4.

Beier et al. [63] conducted a TRT in a well-controlled laboratory environment to obtain a reference dataset for a model validation purpose and this is publicly available. For verification, we applied the developed Bayesian inference to the reference TRT data, and the results were compared with the estimated values in Ref. [63].

The parameters used for the reference sandbox TRT are listed in Table B1. The sandbox TRT was conducted for $52 \mathrm{~h}$ but the data for last 14 min were missing in Beier et al.'s published data. Therefore, the data from the elapsed time of 10 $\mathrm{h}$ to $51 \mathrm{~h}$ were used for the inference. The indicator function $I$ used to restrict the parameter space was set as follows: $\lambda_{\text {eff }}=[1.5,4.5], R_{b}=[0.1,0.3]$, and $r_{\sigma}=(0,0.2]$. The other conditions were identical to those applied to the inference using the numerical TRT data. As in Section 4, the number of MCMC was $5 \times 10^{5}$ and the first $1 \times 10^{5}$ samples were not used to construct PPDFs. 
Table B1. Parameters for sandbox TRT data

\begin{tabular}{lll}
\hline Component & Parameter [units] & Value \\
\hline Borehole & Borehole depth $[\mathrm{m}]$ & 18.3 \\
\cline { 2 - 3 } & Borehole diameter $[\mathrm{mm}]$ & 126 \\
\hline U-tube & Outer diameter $[\mathrm{mm}]$ & 33.40 \\
\cline { 2 - 3 } & Inner diameter $[\mathrm{mm}]$ & 27.33 \\
\cline { 2 - 3 } & Shank spacing $[\mathrm{mm}]$ & 53 \\
\cline { 2 - 3 } & Thermal conductivity $[\mathrm{W} /(\mathrm{m} \cdot \mathrm{K})]$ & 0.39 \\
\cline { 2 - 3 } & Volumetric thermal capacity $\left[\mathrm{MJ} /\left(\mathrm{m}^{3} \cdot \mathrm{K}\right)\right]$ & 1.8 \\
\hline Grout & Thermal conductivity $[\mathrm{W} /(\mathrm{m} \cdot \mathrm{K})]$ & 0.73 \\
\cline { 2 - 3 } & Volumetric thermal capacity $\left[\mathrm{MJ} /\left(\mathrm{m}^{3} \cdot \mathrm{K}\right)\right]$ & 3.8 \\
\hline Ground & Thermal conductivity $[\mathrm{W} /(\mathrm{m} \cdot \mathrm{K})]$ & 2.82 \\
\cline { 2 - 3 } & Volumetric thermal capacity $\left[\mathrm{MJ} /\left(\mathrm{m}^{3} \cdot \mathrm{K}\right)\right]$ & $3.2^{* *}$ \\
\hline TRT set values & Average volumetric flow rate $\left[\mathrm{L} / \mathrm{min}^{*}\right]$ & 11.82 \\
\cline { 2 - 3 } & Average heat injection rate $[\mathrm{W}]$ & 1056 \\
\cline { 2 - 3 } & Initial ground temperature $\left[{ }^{\circ} \mathrm{C}\right]$ & 22.0 \\
\hline
\end{tabular}

*The value was not provided in Ref. [63], but in Ref. [77], the volumetric thermal capacity of grout was estimated and provided.

${ }^{* * *}$ The value was not provided in Ref. [63]. The volumetric thermal capacity of ground specified in the table was obtained from personal communication with Prof. Beier.

Using the $4 \times 10^{5}$ samples, the PPDFs and box plots of $\lambda_{e f f}$ and $R_{b}$ were created and are shown in Fig. B1. The results of Beier et al.'s work [63], and the PM, MAP, and 95\% CI drawn from PPDFs are summarized in Table B2. The results from Bayesian inference were close to the estimation results in Ref. [63].

Using the PM and $95 \% \mathrm{CI}$ of $\lambda_{\text {eff }}$ and $R_{b}$ as inputs to the ILS model, temperature responses were modeled and compared with the measured temperature of sandbox TRT data (Fig. B2). The temperature response generated using the PM agreed well with the measured temperature. It can be seen that the temperature range generated using the $95 \% \mathrm{CI}$ covers the entire range of the measured temperature.
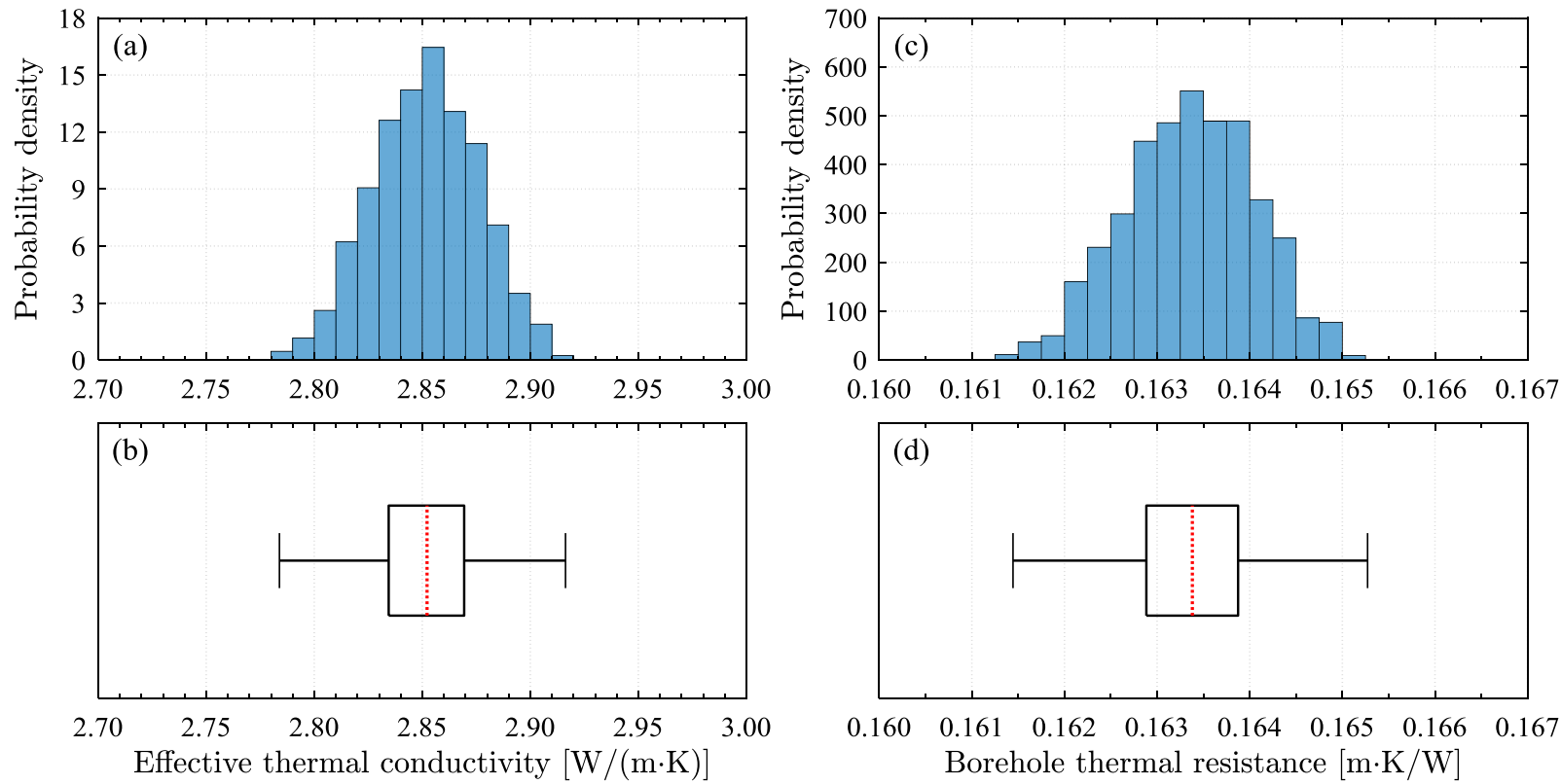

Fig.B1. Normalized probability density functions (PDFs) and box plots: (a) PDF of $\lambda_{e f f}$, (b) box plot of $\lambda_{e f f}$, (c) PDF of $R_{b}$, and (d) box plot of $R_{b}$. 
Table B2. Comparison between the original results [63] and Bayesian inference (PM: posterior mean, MAP: maximum a posteriori, $\mathrm{CI}$ : credible interval).

\begin{tabular}{lll}
\hline Parameter [unit] & $\begin{array}{l}\text { Effective thermal } \\
\text { conductivity } \\
{[\mathrm{W} /(\mathrm{m} \cdot \mathrm{K})]}\end{array}$ & $\begin{array}{l}\text { Borehole thermal } \\
\text { resistance } \\
{[\mathrm{m} \cdot \mathrm{K} / \mathrm{W}]}\end{array}$ \\
\hline $\begin{array}{l}\text { Independent probe } \\
\text { measurement }\end{array}$ & 2.82 & 0.173 \\
\hline $\begin{array}{l}\text { Deterministic } \\
\text { (ILS model) }\end{array}$ & 2.91 & 0.164 \\
\hline $\begin{array}{l}\text { Deterministic } \\
\text { (Composite model [78]) }\end{array}$ & 2.94 & 0.165 \\
\hline $\begin{array}{l}\text { Deterministic } \\
\text { (1D numerical model [79]) }\end{array}$ & 2.84 & 0.187 \\
\hline Bayesian PM & 2.85 & 0.163 \\
\hline Bayesian MAP & 2.85 & 0.163 \\
\hline $95 \%$ CI & $2.80-2.91$ & $0.162-0.165$ \\
\hline
\end{tabular}

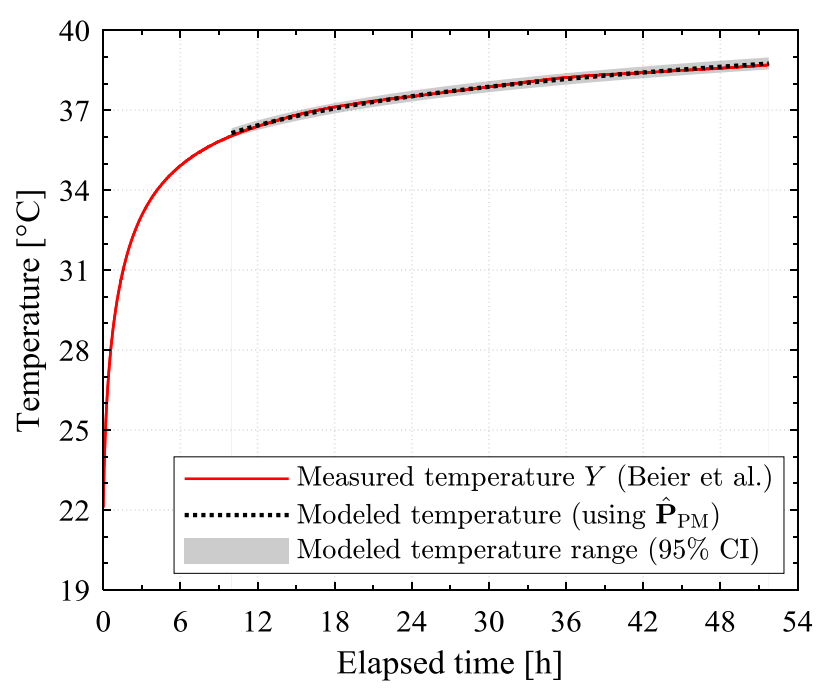

Fig. B2. Sandbox temperature response data used for Bayesian inference, temperature response modeled using point estimates based on the posterior mean, and upper and lower bounds of the temperature modeled using the $95 \%$ credible intervals of the estimates. 
September 20, 2017

Jinyue Yan

Editor-in-Chief

Applied Energy

Dear Dr. Yan,

I, along with my coauthors Hideki Kikumoto, Ruchi Choudhary, and Ryozo Ooka, would like to ask you to reconsider the attached manuscript, titled "Bayesian Inference for Thermal Response Test Parameter Estimation and Uncertainty Assessment" for publication in Applied Energy as an original research article.

The manuscript has been carefully rechecked and appropriate changes have been made in accordance with the reviewers' suggestions. The responses to their comments have been prepared and are attached.

In response to suggestions and comments by Reviewer \#1, we have added richer descriptions and rationales where readers might have the same questions as the reviewer.

Regarding comments from Reviewer \#3, we have addressed all suggestions.

Reviewer \#4's major concern was verification using experimental TRT data. Using the reference sandbox TRT data the reviewer mentioned, we conducted additional verification and confirmed the validity of the proposed stochastic estimation method.

Additional details concerning how our paper was altered in response to the reviewers' comments can be found in the attached document entitled "Response to Reviewers."

We hope that these revisions will be sufficient for publication of the paper in Applied Energy. Please let us know if you have any further concerns that you would like us to address.

We believe that our study makes a significant contribution to the field of ground-source heat pumps (GSHPs) because a stochastic estimation method based on Bayesian statistics has never been reported in the field. Moreover, the proposed estimation method can facilitate the design of reliable ground-source heat pumps with reduced operation risks.

We thank you and the reviewers for the thoughtful suggestions and insights, which have enriched the manuscript and produced a more balanced and better account of the research. We hope that the revised manuscript is now suitable for publication in your journal.

Thank you for your consideration. I look forward to hearing from you.

Sincerely,

Wonjun Choi

Institute of Industrial Science,

The University of Tokyo,

4-6-1 Komaba, Meguro-ku,

Tokyo 153-8505, Japan

Tel.: +81-3-5452-6434

Fax: +81-3-5452-6432

E-mail: wonjun@iis.u-tokyo.ac.jp 


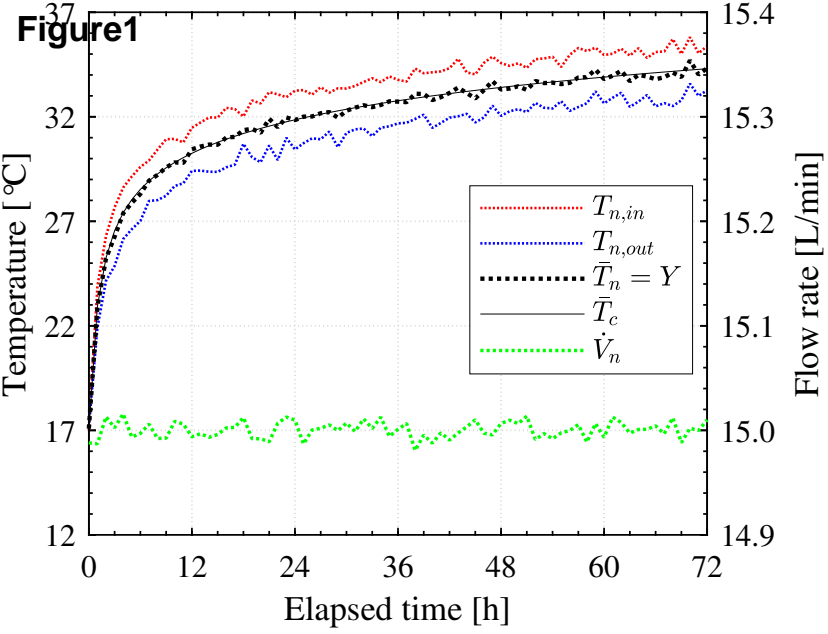




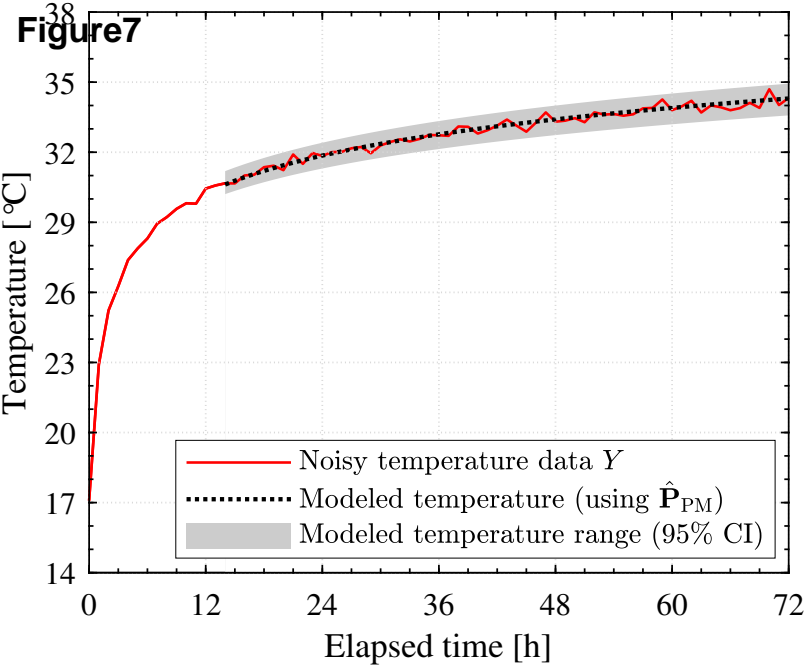




\section{$\begin{array}{lllllll}0 & 1500 & 3000 & 4500 & 6000 & 7500 & 9000\end{array}$}

\subsection{4}



0.171

0.168

0.165

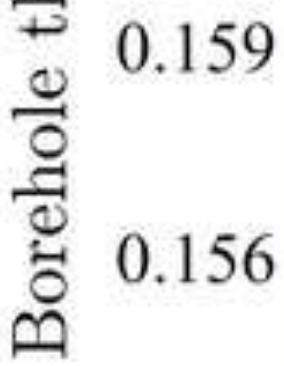

0.153

1.60
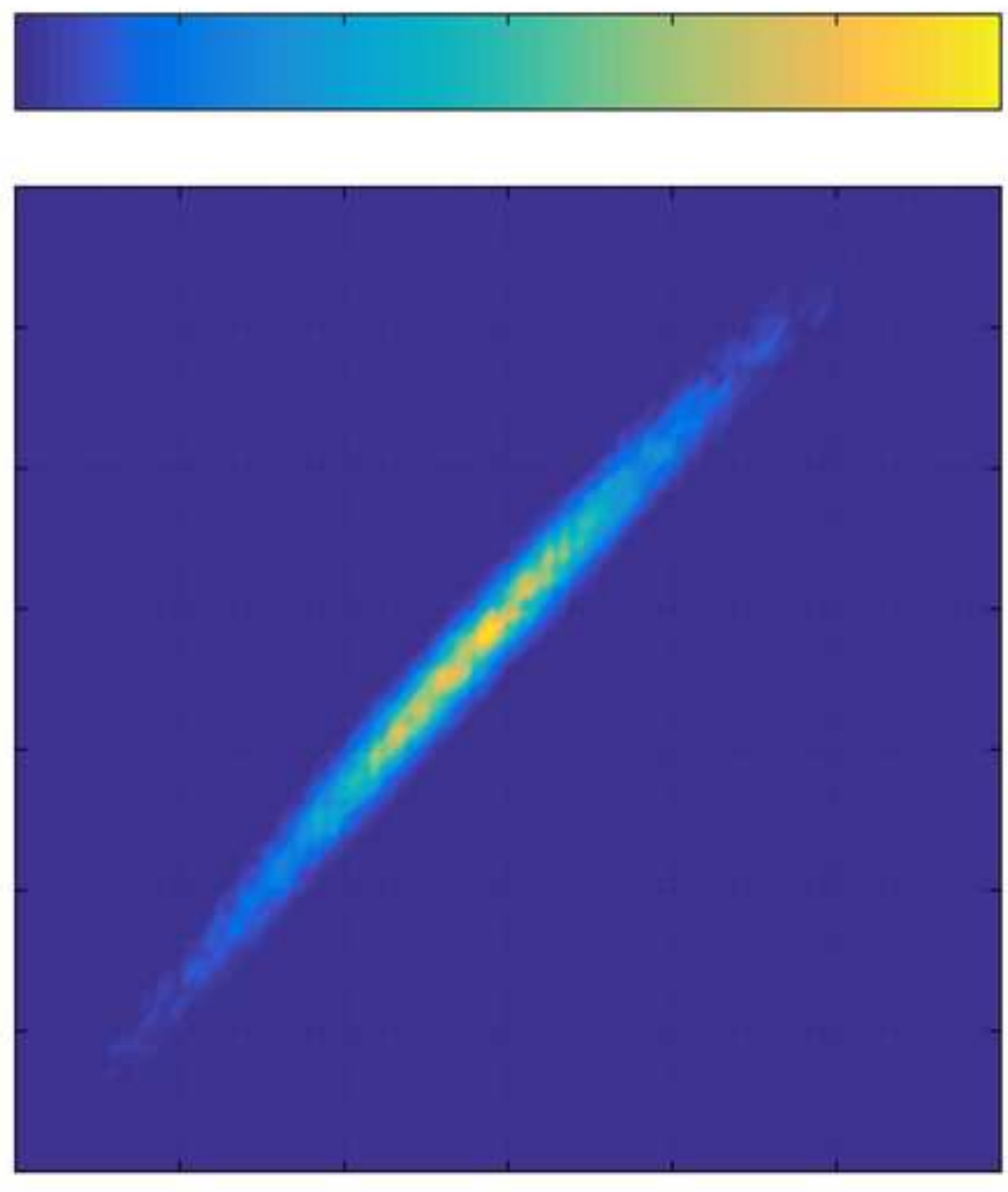

0.162

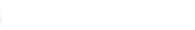

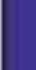

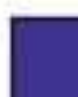

\footnotetext{
.
} 


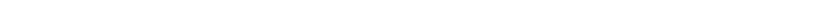




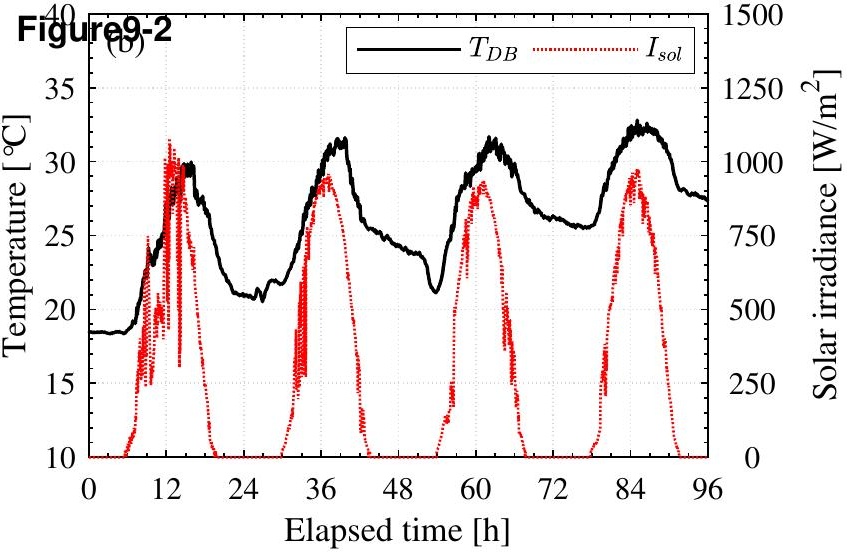




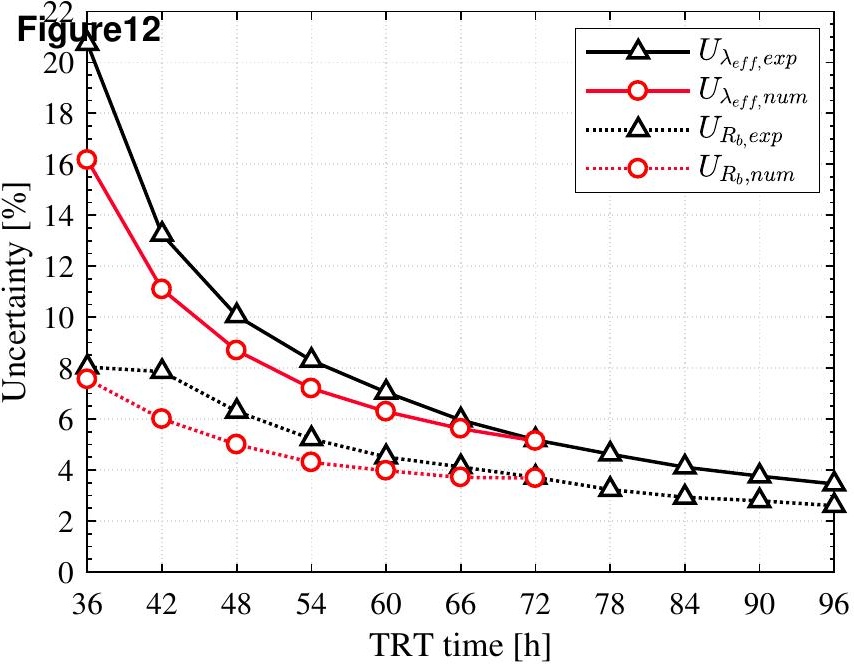




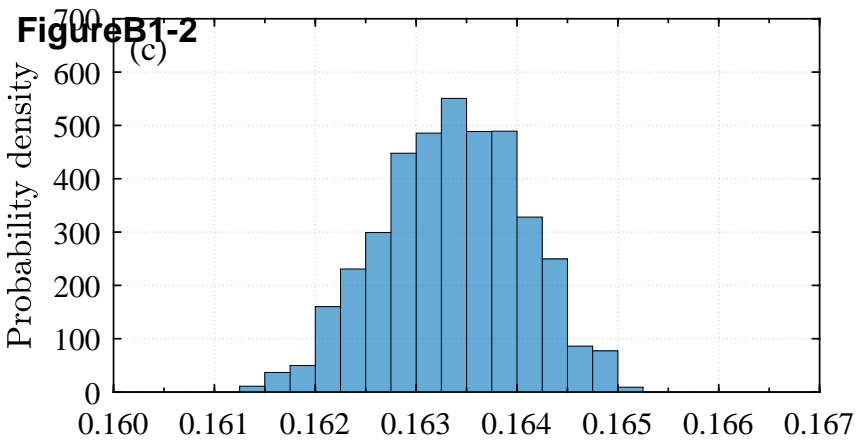

(d)

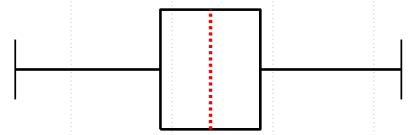

$\begin{array}{llllllll}0.160 & 0.161 & 0.162 & 0.163 & 0.164 & 0.165 & 0.166 & 0.167\end{array}$ Borehole thermal resistance $[\mathrm{m} \cdot \mathrm{K} / \mathrm{W}]$ 
FiğureB2'

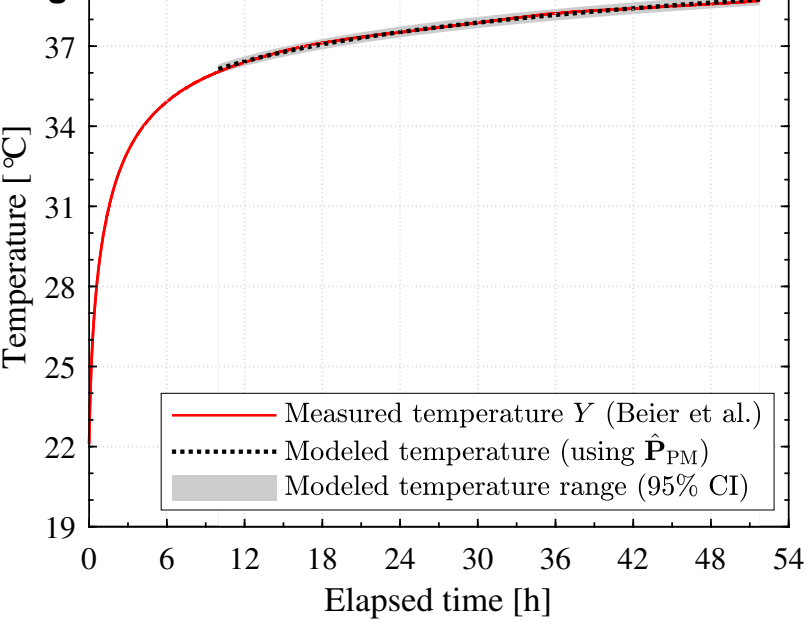

